\title{
Comparison of aerosol chemistry transport model simulations with lidar and Sun photometer observations at a site near Paris
}

\author{
A. Hodzic, ${ }^{1}$ H. Chepfer, ${ }^{1}$ R. Vautard, ${ }^{1}$ P. Chazette, ${ }^{2}$ M. Beekmann, ${ }^{3}$ B. Bessagnet, ${ }^{4}$ \\ B. Chatenet, ${ }^{5}$ J. Cuesta, ${ }^{1}$ P. Drobinski, ${ }^{3}$ P. Goloub, ${ }^{6}$ M. Haeffelin, ${ }^{1}$ and Y. Morille ${ }^{1}$ \\ Received 4 March 2004; revised 6 May 2004; accepted 29 June 2004; published 1 December 2004.
}

[1] The ability of the aerosol chemistry transport model CHIMERE to simulate the vertical aerosol concentration profiles at a site near the city of Paris is evaluated using routine elastic backscatter lidar and Sun photometer measurements. The comparisons of model aerosols with measurements are carried out over a full year time period between October 2002 and September 2003. The methodology we propose here is new: From the model concentration outputs (optical properties varying with chemical composition and mass vertical distribution) we simulate the lidar backscattering profiles and compare them with the observed ones. The comparisons demonstrate the ability of the model to reproduce correctly the aerosol vertical distributions and their temporal variability. However, the aerosol load within the boundary layer is generally underestimated by the model, in particular during the afternoon hours and the summertime period. Several sensitivity tests indicate that this underestimation may have two origins: the lack of secondary organic and, to a lesser extent, mineral aerosols inside the model. The second deficiency is due to the absence of erosion/resuspension of soil material in the primary aerosol sources considered here; the first deficiency is probably due to incomplete knowledge about the formation of organic species in a photochemically active atmosphere. The results also show that the particles ranging from 0.08 to $1.25 \mu \mathrm{m}$ in radius represent more than $89 \%$ of the volume backscattering at $532 \mathrm{~nm}$, while the coarse particles are not efficient in terms of optical properties. The missing aerosol mass must therefore be found within the accumulation mode. INDEX TERMS: 0305 Atmospheric Composition and Structure: Aerosols and particles $(0345,4801) ; 0345$ Atmospheric Composition and Structure: Pollution —urban and regional (0305); 0394 Atmospheric Composition and Structure: Instruments and techniques; KEYWORDS: aerosol modeling, aerosol optical properties, lidar profile, model validation, vertical distribution of aerosols

Citation: Hodzic, A., et al. (2004), Comparison of aerosol chemistry transport model simulations with lidar and Sun photometer observations at a site near Paris, J. Geophys. Res., 109, D23201, doi:10.1029/2004JD004735.

\section{Introduction}

[2] In the lower troposphere anthropogenic aerosols have a significant impact on health and visibility [e.g., Bennet et al., 1985; Lurmann et al., 1997; Eleftheriadis et al., 1998] especially in the vicinity of large cities like Paris where aerosols may result both from direct emissions and from secondary formation. Their concentration and composition vary spatially and temporally because of numerous sources, meteorological conditions and aerosol dynamical processes,

\footnotetext{
${ }^{1}$ Laboratoire de Météorologie Dynamique, Institut Pierre-Simon Laplace, Palaiseau, France.

${ }^{2}$ Laboratoire des Sciences du Climat et de l'Environnement, Institut Pierre-Simon Laplace, Gif sur Yvette, France.

${ }^{3}$ Service d'Aéronomie, Institut Pierre-Simon Laplace, Paris, France.

${ }^{4}$ Institut National de l'Environnement Industriel et des Risques, Verneuil en Halatte, France.

${ }^{5}$ Laboratoire Interuniversitaire des Systèmes Atmosphériques, Créteil, France.

${ }^{6}$ Laboratoire d'Optique Atmosphérique, Lille, France.

Copyright 2004 by the American Geophysical Union. 0148-0227/04/2004JD004735
}

such as nucleation, condensation, evaporation, and coagulation. Some of them are not completely understood today. In order to improve our knowledge and quantify the aerosol impact on the environment, aerosol monitoring and modeling have become a real scientific challenge.

[3] In order to predict aerosol concentrations during pollution events, to understand the processes involved and to test the theoretical knowledge about these processes against observations, scientists have developed complex, fully three-dimensional (3-D) air quality models. Most of these models now include the particulate matter components and the associated physics and chemistry [Hass et al., 2003]. The chemistry transport models (CTMs) have been extensively tested against ozone and other gas-phase concentration observations, but the evaluation of the aerosol components is largely incomplete. In Europe, the most comprehensive evaluation has been conducted by Hass et al. [2003] comparing simulations from six models of different complexity of the aerosol module (bulk, modal, sectional approach) to surface measurements of inorganic ions gathered from the EMEP and national air quality networks during April to September 1995. For sulfate and ammonium 
particles, most of the comparisons for station averages fall within a factor of two without a systematic bias (taking the six models altogether). Nitrate is systematically overestimated by models. The CHIMERE model used in this study shows normalized errors between 50 and $80 \%$ for inorganic ions and $40-90 \%$ for $\mathrm{PM}_{10}$ (particles smaller than $10 \mu \mathrm{m}$ ), in comparison to summer 2000 data. Systematic comparison of other aerosol components such as soot and organic carbon has not yet been performed in Europe. The evaluation of the space-time variability of the aerosol concentration simulated by $3-\mathrm{D}$ aerosol CTMs is therefore fairly incomplete and further efforts of model evaluation have to be made.

[4] Aerosol lidar measurements represent another type of available data in a great number of sites [Bösenberg et al., 2003]. Today, these data are not used for the validation of aerosol chemistry transport models near urban areas, mainly because the retrieval of the aerosol concentration from the lidar signal is still difficult, since there is no one-to-one correspondence between the lidar backscatter signal and the aerosol concentration, because backscattering properties of the aerosol mixture depends on its composition and on relative humidity [Hänel, 1976]. However, it is possible to link the chemical composition of the aerosol to its optical properties through the refractive index which is known for the major aerosol components [Chazette and Liousse, 2000]. Some studies have been carried out for characterizing urban aerosols using lidar observations over the Tessaloniki area [e.g., Balis et al., 1999]. Also, lidar measurements have been used for the evaluation of desert dust aerosol transport forecast models [Guelle et al., 2000; Ansmann et al., 2003], but lidar measurements have never been used for the validation of aerosol pollution models. Elastic and inelastic backscatter lidar profiles contain valuable information on the vertical distribution of aerosol layers. When these lidar profiles are taken at the same site over a long time period (several days or months), they provide the basis for a statistical validation of the model, which allows a better understanding of the transport and mixing processes over a variety of meteorological situations [Bösenberg et al., 2003].

[5] Sun photometers also bear a complementary potential for aerosol chemistry transport model validation. Under clearsky conditions, these instruments measure the integrated optical properties of the aerosols present in the atmospheric column (optical thickness, scattering albedo and complex refractive index). Sun photometer measurements are now taken routinely in the Aerosol Robotic Network (AERONET) (available at http://aeronet.gsfc.nasa.gov) [Holben et al., 1998]; therefore numerous measurements are available in several sites over the globe. Sun photometer measurements are very important constraints for the lidar inversion procedure as shown during INDOEX (Indian Ocean Experiment) by Pelon et al. [2002] or Chazette [2003]. They are also important to validate spaceborne observations [e.g., Moulin et al., 1997]. Nevertheless, so far these measurements have mostly been used for the validation of global mineral aerosol transport models [e.g., Guelle et al., 2000].

[6] In this article, we use the quasi-continuous measurements taken at the "Site Instrumental de Recherche par Télédétection Active" (SIRTA) [Haeffelin et al., 2003] in order to assess the ability of the aerosol chemistry transport model CHIMERE [Bessagnet et al., 2004; Schmidt et al., 2001] to simulate the space-time variability of the aerosol concentrations in a suburban environment. This paper is also designed to propose a new model validation methodology using elastic lidar measurements by directly simulating the lidar signal from the model outputs and comparing the resulting profiles to the observed actual lidar signals. The optical properties of the model aerosols are compared, in a statistical manner, to measurements obtained with a Sun photometer of the AERONET network also located at the SIRTA site. All these comparisons are made over several tens of days spread over a full year. Differences between summertime and wintertime results are discussed. In section 2, the chemistry transport model CHIMERE and its aerosol module are briefly described. In section 3 the available observations are presented. Section 4 describes the method used for the comparison of observed and modeled data, and finally the results of the comparison with Sun photometer and lidar are presented and discussed in sections 5 and 6 . Section 7 contains our conclusions.

\section{Model Description}

\subsection{General Model Configuration}

[7] CHIMERE is a 3-D chemistry transport model that simulates gas-phase chemistry [Schmidt et al., 2001; Vautard et al., 2001], aerosol formation, transport, and deposition [Bessagnet et al., 2004] at European and urban scales. It has been designed with the aim of performing both episodic and long-term simulations at various spatial scales ranging from local to regional scale, on a personal computer or a workstation. The latest versions of the model and their documentation are available for download on the Web site http://euler.lmd.polytechnique.fr/chimere. The general performances of the model for the simulation of ozone and aerosols are given by Schmidt et al. [2001], Vautard et al. [2001], and Bessagnet et al. [2004] and also in a more recent application over Bangkok (B. Zhang et al., Comparison of the UAM-V/SAIMM and CHIMERE/ECMWF photochemical modeling system performance in a tropical urban area, submitted to Journal of the Air and Waste Management Association, 2004). The model has also been used for other applications such as sensitivity to emissions [Derognat et al., 2003; Menut, 2003; Schmidt and Martin, 2003; Sillman et al., 2003] or ozone data assimilation [Blond et al., 2003, Blond and Vautard, 2004].

[8] In the present application, the model is run at mesoscale in a domain covering the Paris greater metropolitan area (Figure 1). The model domain is described by Vautard et al. [2001, 2003]. It is $150 \mathrm{~km}$ wide with a 6-km grid size resolution. Compared to previous studies, vertical resolution of the small-scale model version is increased to 20 sigmapressure levels extending up to $500 \mathrm{hPa}$ that covers the boundary layer and the lower part of the free troposphere.

[9] Boundary conditions are provided by a prior regional, large-scale simulation using a model configuration similar to that used by Bessagnet et al. [2004]. In this case the model domain covers Western Europe with a $0.5^{\circ}$ resolution. The vertical resolution of this large-scale configuration is also coarse, with eight vertical levels also extending from ground to $500 \mathrm{hPa}$. As in the Vautard et al. [2003] work we use a one-way nesting procedure. Boundary conditions of regional simulations are taken from climatologies of the MOZART global chemistry transport model [Horowitz et 


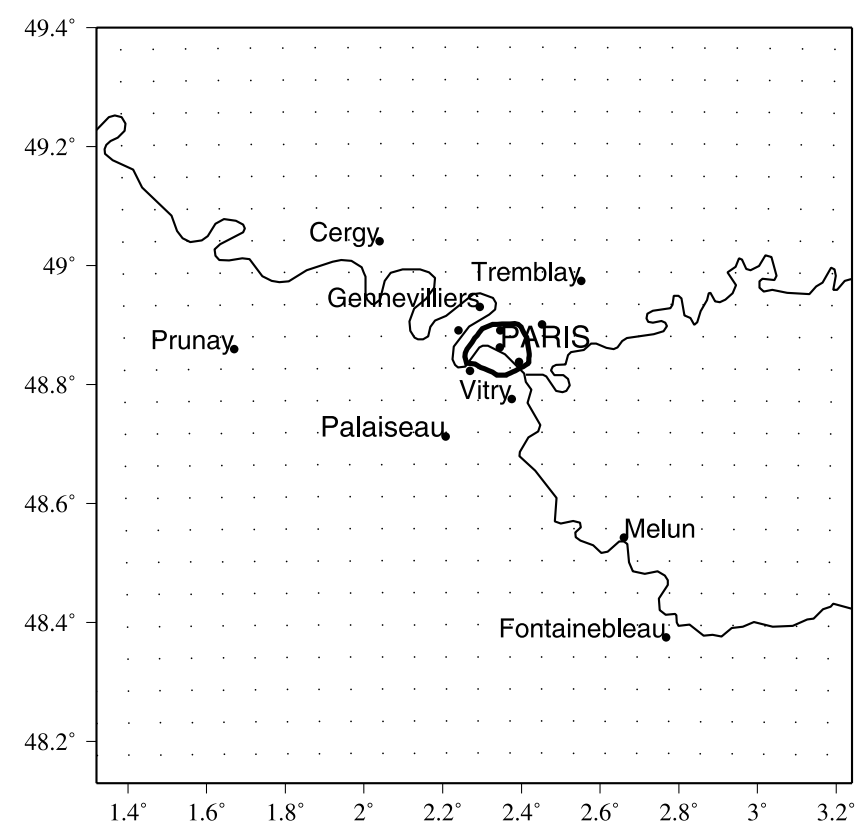

Figure 1. The model horizontal grid (dots) and domain. A few sites where air quality is monitored by the AIRPARIF network are indicated on the figure, as well as the site where lidar observations are made (Palaiseau).

al., 2003]. For aerosol species, zero concentrations are assumed at outer boundaries.

[10] The model simulates the concentration of 44 gaseous species and 6 aerosol chemical compounds. The gas-phase chemistry scheme [Lattuati, 1997] has been extended to include sulfur aqueous chemistry, secondary organic chemistry and heterogeneous chemistry of HONO [Aumont et al., 2003] and nitrate [Jacob, 2000].

\subsection{Aerosol Module}

[11] The population of aerosol particles is represented using a sectional formulation, assuming discrete aerosol size sections and considering the particles of a given section as homogeneous in composition (internally mixed). Like in the work of Bessagnet et al. [2004], we use six diameter bins ranging between $10 \mathrm{~nm}$ and $40 \mu \mathrm{m}$, with a geometric increase of bin bounds. The aerosol module accounts for both inorganic and organic species, of primary or secondary origin, such as, primary particulate matter (PPM), sulfates, nitrates, ammonium, secondary organic species (SOA) and water. PPM is composed of primary anthropogenic species such as elemental and organic carbon and crustal materials. In the model, ammonia, nitrate, and sulfate are considered in aqueous, gaseous, and particulate phases.

[12] Sulfate is produced from gaseous and aqueous oxidation of $\mathrm{SO}_{2}$ [Berge, 1993; Hoffman and Calvert, 1985; Lee and Schwartz, 1983]. Nitric acid is produced in the gas phase by $\mathrm{NO}_{x}$ oxidation, but also by heterogeneous reaction of $\mathrm{N}_{2} \mathrm{O}_{5}$ on the aerosol surface [Jacob, 2000]. Issued directly from primary emissions, ammonia is converted into aerosol phase (mainly ammonium-nitrate and ammoniumsulfate) by neutralization with nitric and sulfuric acids. Secondary organic aerosols are formed by condensation of biogenic and anthropogenic hydrocarbon oxidation products, they are partitioned between the aerosol and gas phase through a temperature-dependent partition coefficient [Pankow, 1994]. A lookup table method, set up from the ISORROPIA equilibrium model [Nenes et al., 1998, 1999], is used to calculate concentrations at equilibrium for inorganic aerosols composed of sulfate, nitrate, ammonium, and water. Dynamical processes influencing aerosol population are also described. New particles are formed by nucleation of $\mathrm{H}_{2} \mathrm{SO}_{4}$ [Kulmala et al., 1998]. Particles' growth due to the coagulation and condensation of semivolatile species is also taken into account. The coagulation process applied for multicomponent system is calculated as in the work of Gelbard and Seinfeld [1980]. Aerosols can be removed by dry deposition [Seinfeld and Pandis, 1998] and wet removal [Guelle et al., 1998; Tsyro, 2002]. Particles can be scavenged either by coagulation with cloud droplets or by precipitating drops. Moreover, particles act efficiently as cloud condensation nuclei to form new droplets.

\subsection{Meteorological Forcing}

[13] CHIMERE requires several meteorological variables as input. These are wind, temperature, mixing ratio for water vapor and liquid water in clouds, $2 \mathrm{~m}$ temperature, surface heat and moisture fluxes and precipitation. In previous CHIMERE applications, meteorological fields from the European Centre for Medium-Range Weather Forecasts were used. Owing to the relatively high resolution required for the present application, we use a mesoscale meteorological model, MM5 [Dudhia, 1993], in order to force the CHIMERE simulations. Meteorological mesoscale simulations are performed with a two-way nesting procedure with two domains of respective resolutions $15 \mathrm{~km}$ and $5 \mathrm{~km}$. The smallest meteorological domain encompasses the CHIMERE domain. In order for the synoptic flow to stay close to meteorological analyses, the $15-\mathrm{km}$ resolution meteorological simulation uses nudging for all variables with a coefficient of $10^{-4} \mathrm{~s}^{-1}$. Regional CHIMERE simulations are forced by regional simulations using MM5 with a $36-\mathrm{km}$ resolution.

\subsection{Emissions}

[14] For the large-scale simulations, the anthropogenic emissions for $\mathrm{NO}_{x}, \mathrm{CO}, \mathrm{SO}_{2}, \mathrm{NMVOC}$ and $\mathrm{NH}_{3}$ gas-phase species for 10 anthropogenic activity sectors (as defined by the SNAP categories) are provided by EMEP (available at http://www.emep.int) with spatial resolution of $50 \mathrm{~km}$. Emissions of primary particulate matter $\mathrm{PM}_{10}$ and $\mathrm{PM}_{2.5}$ are taken from the TNO (Netherlands Organization for Applied Scientific Research) European inventory (available at http://www.air.sk/tno/cepmeip/).

[15] For the local-scale simulations around Paris, the gasphase emission inventory built by the AIRPARIF air quality-monitoring network is used. This emission inventory, valid in principle for year 1998, is described and evaluated by Vautard et al. [2003]. However, no inventory of particulate matter emission was available at the time of the study. In order to have physically meaningful PM emissions, we use the regional-scale $\mathrm{PM}$ to $\mathrm{NO}_{x}$ annual emission ratios, for each first-level activity sector available in the TNO emissions in the neighborhood of Paris, and apply the same ratios for the small-scale distribution of PM emissions in the Ile-de-France area. PM emissions are therefore spatially distributed exactly as $\mathrm{NO}_{x}$ for each first-level SNAP activity 
sector, while PM emission totals are coherent with the EMEP inventory. The use of $\mathrm{PM} / \mathrm{NO}_{x}$ ratios instead of ratios to another gaseous species is motivated by the assumption that most of the urban aerosol emissions are of small size and come from combustion and more particularly from the road traffic sector.

\subsection{Model Simulations}

[16] The model is run in time slices of five consecutive days with full restarts, so that the concentrations are continuous in time. Both regional and small-scale versions are run in this way. This whole set of simulations starts on 28 September 2002 and ends on 2 October 2003. It is initialized with a first spin-up run of 3 days. A small period of time, from 1 January to 9 February 2003 is not simulated because of missing NCEP analyses in our database.

\section{Experimental Setup}

[17] Measurements used in this comparison have been performed quasi continuously in Palaiseau, in the southwestern suburb of Paris $\left(2.208^{\circ} \mathrm{E}, 48.713^{\circ} \mathrm{N}\right)$, France, by two different instruments, an elastic backscatter lidar and a Sun photometer, at the French observatory SIRTA [Haeffelin et al., 2003] initiated by Institut Pierre-Simon Laplace (IPSL). Routine measurements at SIRTA offer an exceptional framework to compare model simulations and observations over long time periods.

\subsection{Elastic Backscatter Lidar}

[18] The elastic backscatter lidar provides routine measurements at $532 \mathrm{~nm}$ since year 2000, in the frame of the European lidar network EARLINET [Bösenberg et al., 2003]. The lidar system is based on Nd-YAG pulsed laser emitting at $1064 \mathrm{~nm}$. The emission frequency is doubled $(532 \mathrm{~nm})$ and linearly polarized. Backscattered photons are collected through a large narrow-field-of-view (NFOV) telescope that ranges from ground to $15 \mathrm{~km}$ and smaller wide-field-of-view (WFOV) telescope that ranges from ground to $6 \mathrm{~km}$. Vertical raw resolution is of $15 \mathrm{~m}$. The laser pulse repetition frequency is $20 \mathrm{~Hz}$ and the temporal sampling is made every $10 \mathrm{~s}$, with power of $100 \mathrm{~mJ}$ pulse $^{-1}$. It is important to notice that the lidar signal must be corrected from the overlap factor below about $800 \mathrm{~m}$ caused by the incomplete overlap between the telescope and the laser beam [e.g., Sicard et al., 2002; Chazette, 2003]. This factor can be estimated from the lidar system characteristics given in Table 1.

[19] Each raw lidar vertical profile is normalized to the molecular signal at an aerosol-free level following the method proposed by Fernald et al. [1972]. The altitude of normalization varies with time, but it is registered for each profile to allow comparisons with the simulations (section 6).

\subsection{Sun Photometer}

[20] Another independent data set comes from a CIMEL 318-CE Sun photometer that has operated at SIRTA since July 2002, as part of AERONET network. The Sun photometer instrument performs measurements of the optical thickness at several wavelengths in the visible spectrum. Data are corrected from cloud contamination. For this study, we derive the optical thickness data at $532 \mathrm{~nm}$ from
Table 1. Lidar Characteristics Relative to Overlap Factor Correction $^{\mathrm{a}}$

\begin{tabular}{lc}
\hline \multicolumn{1}{c}{ System Parameters } & Values \\
\hline Field of view & $2 \mathrm{mrad}$ \\
Laser beam divergence & $0.6 \mathrm{mrad}$ \\
Radius of the emitter beam & $3 \mathrm{~mm}$ \\
Diameter of the primary mirror & $208 \mathrm{~mm}$ \\
Diameter of the secondary mirror & $57 \mathrm{~mm}$ \\
Distance between emitted laser beam & $60 \mathrm{~cm}$ \\
$\quad$ and telescope optical axis &
\end{tabular}

${ }^{a}$ Lidar characteristics relative to overlap factor correction for the widefield-of-view telescope are given.

the 440 and $670 \mathrm{~nm}$ channels using the Angström relation [Angström, 1964]:

$$
\delta_{532}=\delta_{670}\left(\frac{532}{670}\right)^{-\alpha},
$$

where $\alpha$ is the Angström exponent defined as equation (2)

$$
\alpha=\ln \left(\frac{\delta_{440}}{\delta_{670}}\right) / \ln \left(\frac{670}{440}\right) .
$$

Direct measurement of the aerosol optical thickness gives a maximal absolute uncertainty of 0.02 , independent of aerosol load [e.g., Holben et al., 1998]. The relative uncertainty on $\alpha$ is a function of the optical thickness. As proposed by [Hamonou et al., 1999], the relative error on $\delta_{532}$ can be expressed as

$$
\frac{\Delta \delta_{532}}{\delta_{532}}=\left(1+\frac{\ln \left(\frac{532}{440}\right)}{\ln \left(\frac{670}{440}\right)}\right) \frac{\Delta \delta_{440}}{\delta_{440}}+\left(\frac{\ln \left(\frac{532}{670}\right)}{\ln \left(\frac{670}{440}\right)}\right) \frac{\Delta \delta_{670}}{\delta_{670}} .
$$

In our study the value of $\frac{\Delta \delta_{532}}{\delta_{532}}$ does not exceed $8 \%$ in an aerosol layer of $\delta 440>0.3$.

[21] The Angström exponent depends mostly on the aerosol size distribution: Small values correspond to large particles such as sea salt or mineral particles, whereas values between 1 and 2 are found in polluted air masses containing submicron-sized particles such as sulfates, nitrates and carbonaceous aerosol [Liousse et al., 1995]. As suggested by Dubovik et al. [2001], we considered aerosol optical thickness data only when Angström exponent is higher than 0.6. This filtering procedure has the advantage of eliminating all cloud-contaminated data in a conservative manner.

[22] The Sun photometer measurements also allows to determine the aerosol optical properties such as the integrated single-scattering albedo (SSA) at $532 \mathrm{~nm}$, deduced from the channels at 440 and $670 \mathrm{~nm}$ using the Dubovik algorithm [Dubovik and King, 2000; Dubovik et al., 2000], and the real $(n)$ and imaginary $(k)$ parts of the refractive index at $673 \mathrm{~nm}$. The analysis showed [Dubovik et al., 2001] that an accurate SSA (within accuracy of 0.03 ) and refractive index retrievals (errors about $30 \%$ for $k$ and 0.04 for $n$ ) can be provided only for high aerosol loading $\left(\delta_{440}>\right.$ $0.3)$. Therefore, in this study only the measurements corresponding to a high aerosol loading are considered.

\section{Comparison Methodology}

[23] In order to compare aerosol lidar data with model outputs, we use an original approach: The aerosol lidar 


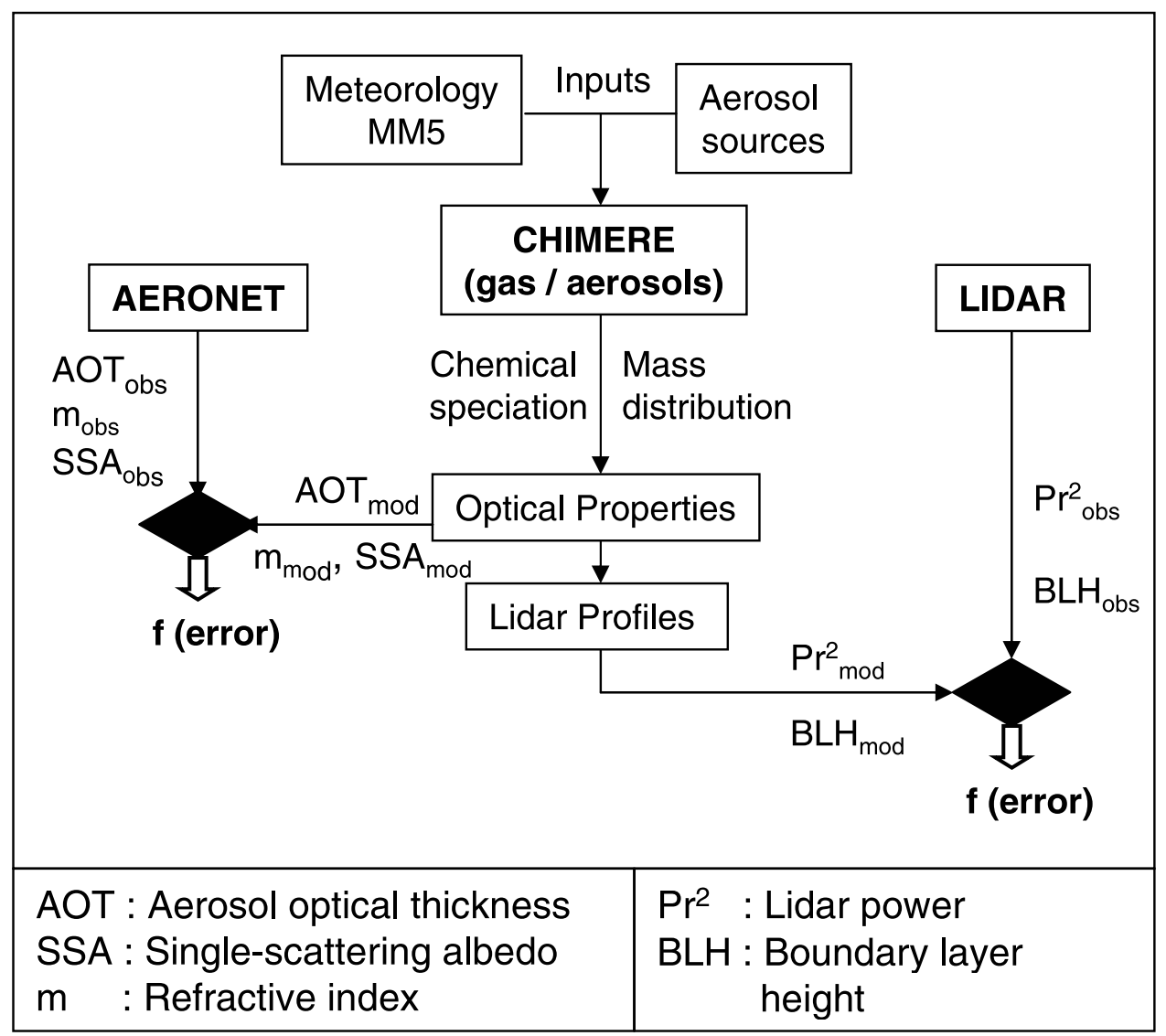

Figure 2. Diagram describing the method of the comparison of the model results with lidar and photometer data.

signal is directly simulated from the model aerosol vertical profiles. More precisely, the lidar equation [Measures, 1984] is solved using the optical properties and the number or the mass concentration of particles in each size section and altitude layer of the model. This approach has the advantage of minimizing the number of assumptions as the simulation of the aerosol lidar signal does not require adding new hypothesis to the ones already used in the model parameterizations. In this section we describe the method used to compute both the aerosol optical properties and the aerosol lidar signal from the model outputs (Figure 2).

\subsection{Aerosol Optical Properties}

[24] The aerosol and molecular optical properties such as extinction, backscattering coefficients, and backscatter phase function for each size section of the model are computed following the Rayleigh [Ulaby et al., 1943] and Mie [1908] theories of scattering and absorption of electromagnetic radiation by homogeneous spheres. The calculation was done using the calculated model refractive index ( $m=n-i k)$ associated to the composition of the aerosol in each size bin. In our study we used the refractive index for wet particles in order to take into account the effect of water vapor on hydrophilic aerosols. It was computed from the dry one using the Hänel's [1976] relation:

$$
\begin{gathered}
m_{\text {wet }}=m_{\mathrm{H}_{2} \mathrm{O}}+\left(m-m_{\mathrm{H}_{2} \mathrm{O}}\right)\left(r / r_{\text {wet }}\right)^{3} \\
r_{\text {wet }}=r(1-\mathrm{RH})^{-e}
\end{gathered}
$$

where $r$ and $r_{\text {wet }}$ are the radius of dry and wet particles, respectively; $m$ and $m_{\text {wet }}$ are the corresponding refractive indexes; and RH is the relative humidity. The coefficient $e$ depends on the type of aerosol and is equal to 0.285 for sulfate aerosol and has been established to be equal to 0.25 for particulate organic matter over Tessaloniki by Chazette and Liousse [2000].

[25] This previous value is very close to the sulfate one, and as the Paris aerosol is a mixture of water soluble and carbonaceous compounds, the value $e=0.285$ is kept hereafter. In any case, the sensitivity test shows that using the value $e=0.25$ the results will be changed by less than $1 \%$. The dry refractive index used for different aerosol species are given in Table 2 [Mallet, 2003].

\subsection{Simulation of Lidar Profile}

\subsubsection{Lidar Equation}

[26] The lidar elastic backscattered signal is defined by the classical lidar equation [e.g., Collis and Russell, 1976]:

$$
\begin{aligned}
P(z) \cdot z^{2}= & C_{L} \cdot F(z) \cdot\left(\beta_{m}(z)+\beta_{a}(z)\right) \\
& \cdot \exp \left(-2 \cdot \int_{0}^{z}\left(\alpha_{m}(z)+\alpha_{a}(z)\right) d z\right)
\end{aligned}
$$

where $C_{L}$ is the constant geometric factor depending on the technical characteristics of the emitting and receiving optics (instrumental constant and transmitted energy) and $F(z)$ is the overlap factor that is a function of the emitting and 
Table 2. Refractive Index for Different Aerosol Components at $0 \%$ of Relative Humidity at Wavelength of $550 \mathrm{~nm}^{\mathrm{a}}$

\begin{tabular}{lcc}
\hline \multicolumn{1}{c}{ Aerosols } & Real Part $n$ & Imaginary Part $k$ \\
\hline Primary particulate matter & 1.75 & 0.44 \\
Secondary organic aerosol & 1.55 & 0.05 \\
Water soluble (sulfate, nitrate, ammonium) & 1.53 & $6 \times 10^{-3}$ \\
Mineral dust $^{\mathrm{b}}$ & 1.53 & $5.5 \times 10^{-3}$ \\
Sea salt $^{\mathrm{b}}$ & 1.56 & $6 \times 10^{-3}$ \\
Water & 1.33 & 0 \\
\hline
\end{tabular}

${ }^{\mathrm{a}}$ Source is Mallet [2003].

${ }^{\mathrm{b}}$ The mineral dust issued from soil erosion and resuspension and the sea salt are not considered in the model, but they are used in a sensitivity study.

receiving geometry. $F(z)$ is here calculated for a biaxial lidar system with the characteristics given in Table 1 [Lefrère, 1982]; $\beta_{m}(z)$ and $\beta_{a}(z)$ are respectively the volume backscattering coefficients for the atmospheric molecules and particles $\left(\mathrm{m}^{-1} \mathrm{sr}^{-1}\right)$ respectively, while $\alpha_{m}(z)$ and $\alpha_{a}(z)$ are the corresponding extinction coefficients $\left(\mathrm{m}^{-1}\right)$ at altitude $z$.

[27] The lidar equation is linked to the model outputs by extinction and backscattering coefficients which depend on several parameters, such as the mass distribution of particles $n_{M}\left(\mathrm{~g} \mathrm{~cm}^{-3} \mathrm{~m}^{-1}\right)$ and their refractive index $m$ related to their composition in each size bin [e.g., Seinfeld and Pandis, 1998]:

$$
\begin{gathered}
\alpha_{a}=\int_{0}^{R_{\max }} \cdot \frac{\sigma_{\mathrm{ext}}(m, r)}{\pi \cdot \rho \cdot r^{3}} \cdot n_{M}(r) \cdot d r \\
\beta_{a}=\int_{0}^{R_{\max }} k_{a}(r) \cdot \frac{\sigma_{\mathrm{sca}}(m, r)}{\pi \cdot \rho \cdot r^{3}} \cdot n_{M}(r) \cdot d r
\end{gathered}
$$

where $\rho$ is the particle density $\left(\mathrm{g} \mathrm{cm}^{-3}\right), \sigma_{\text {ext }}$ and $\sigma_{\text {sca }}$ are the extinction and the scattering cross sections $\left(\mathrm{m}^{2}\right)$ of particles, and $k_{a}$ is the aerosol backscatter phase function $\left(\mathrm{sr}^{-1}\right)$. The simulated molecular lidar profile is deduced from vertical profiles of temperature and pressure (Trappes radiosounding) using the method described by Collis and Russell [1976].

\subsubsection{Normalization of the Simulated Lidar Signal}

[28] To compare the simulated lidar profiles with the observed ones, we compute the normalized backscattered power, corrected from the altitude and the geometric overlap:

$$
P(z) z_{\text {norm }}^{2}=\frac{P(z) z^{2}}{P\left(z_{\text {ref }}\right) z_{\text {ref }}^{2}}=\frac{F(z) \cdot \beta(z)}{\beta_{\text {ref }}\left(z_{\text {ref }}\right)} \cdot \exp \left(-2\left(\delta(z)-\delta_{\text {ref }}\left(z_{\text {ref }}\right)\right)\right)
$$

where $\delta(z)$ is the integrated optical thickness due to extinction of lidar signal by the atmospheric molecules and particles. The normalization altitude $z_{\text {ref }}$ is taken at the beginning of an aerosol-free area of the atmosphere, where $F\left(z_{\text {ref }}\right)=1$, independently, for each lidar profile $\left(z_{\text {ref }}>3 \mathrm{~km}\right)$.

\section{Model Validation With the Sun Photometer 5.1. Comparison With AERONET Data}

[29] We now compare model outputs with all available cloud-free data from the Aerosol Robotic Network Sun photometer. The optical properties used for these comparisons are the refractive index, the aerosol optical thickness (AOT) and the single-scattering albedo (SSA). The months during which data were available are indicated in Table 3. Unfortunately, almost no data were available during the fall/ winter period because of almost permanent cloudiness. On the model side, optical properties are calculated as averages over the model column, from the ground to $500 \mathrm{hPa}$. Both observed and simulated monthly mean values are shown together with their respective uncertainty. The error bars correspond to the standard deviation of the monthly mean values, $\pm 2 \sigma / \sqrt{N}$, where $\sigma$ is the standard deviation of the signal and $N$ is the number of available days. For the observations the instrumental error has also been added.

\subsubsection{Refractive Index}

[30] The refractive index is an instructive indicator of the model behavior because it strongly depends on the aerosol chemical composition and its internal structure. Figure 3 shows the integrated monthly mean refractive index, separated into its real and imaginary parts, at $532 \mathrm{~nm}$ for the modeled values and $673 \mathrm{~nm}$ for the observed ones. Since the refractive index of the continental aerosol is rather constant in the visible spectrum [Volz, 1973], we can directly compare those values. The observed real part values range from 1.44 to 1.52 , while the imaginary part values lie between 0.03 and 0.1 . For the real component, the model lies within observed error bars showing a rather good agreement with observations, especially in March and April. For the imaginary component, the differences between simulated and observed values are larger: The model tends to overestimate in winter and spring and to underestimate during summer.

[31] The disagreement between the photometer and the model is probably related to the errors in the aerosol composition. The large uncertainties in the formation of secondary organic aerosols during summer and the lack of mineral dust emission from soil erosion or resuspension are probably the key factors in these discrepancies. Moreover, according to equations (4) and (5), these parameters are also sensitive to relative humidity. A rapid inspection of MM5 humidity profiles as compared with radiosounding reveals an overestimation of the relative humidity by the MM5 model in summer (from 3 to almost $10 \%$ ) that may be

Table 3. Sun Photometer Measurements in Palaiseau, France, From October 2002 to September 2003

\begin{tabular}{lccccc}
\hline & \multicolumn{5}{c}{ Number of Available Photometer Data } \\
\cline { 2 - 6 } \multicolumn{1}{c}{ Month } & $\begin{array}{c}\text { Number of } \\
\text { Days }\end{array}$ & $\operatorname{Re}(\mathrm{m}), \operatorname{Im}(\mathrm{m})^{\mathrm{a}}$ & SSA & $\begin{array}{c}\text { Number of } \\
\text { Days }\end{array}$ & AOT \\
\hline October 2002 & - & - & - & 17 & 47 \\
November 2002 & - & - & - & - & - \\
December 2002 & - & - & - & 4 & 17 \\
January 2003 & - & - & - & - & - \\
February 2003 & 5 & 10 & 10 & 16 & 245 \\
March 2003 & 12 & 29 & 29 & 22 & 585 \\
April 2003 & 5 & 17 & 17 & 26 & 432 \\
May 2003 & 6 & 22 & 17 & 21 & 254 \\
June 2003 & 12 & 21 & 20 & 28 & 355 \\
July 2003 & 4 & 10 & 7 & 27 & 339 \\
August 2003 & 16 & 43 & 42 & 30 & 673 \\
September 2003 & 4 & 10 & 10 & 25 & 612 \\
\hline
\end{tabular}

${ }^{\mathrm{a}} \mathrm{Re}(\mathrm{m})$ is real part of the refractive index; $\operatorname{Im}(\mathrm{m})$ is imaginary part of the refractive index. 

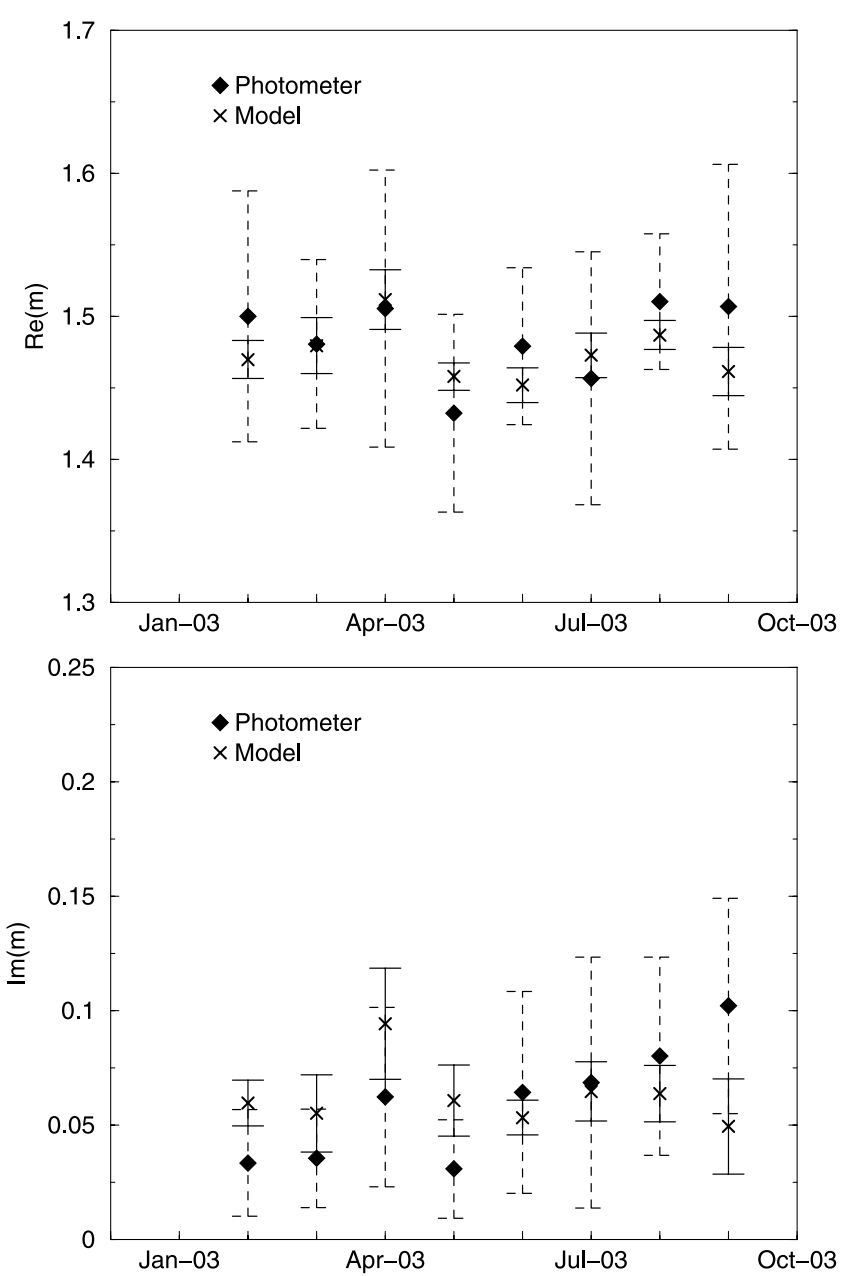

Figure 3. Integrated monthly mean refractive index, (top) real and (bottom) imaginary parts, deduced from Sun photometer measurements at $673 \mathrm{~nm}$ and CHIMERE simulations at $532 \mathrm{~nm}$ close to Paris (Palaiseau, France) between January and September 2003.

responsible for the underestimation of the refractive index values.

\subsubsection{Aerosol Optical Thickness (AOT)}

[32] Figure 4 shows the monthly mean values of the aerosol optical thickness observed as well as those simulated by CHIMERE. The observed AOT varies from 0.18 in December and February to 0.34 in August. It is obvious that the model underestimates the observed AOT values in spring and summer (from $20 \%$ in March to more than $50 \%$ in August), while from October to February the sign of the bias is not clear. The highest values of the optical thickness, greater than 0.5 , are observed during stable atmospheric situations favorable to pollution episodes, as for the case of 26 March 2003, discussed in the following, but also during the great pollution episode associated to the heat wave that occurred in Western Europe during the first two weeks of August 2003.

[33] The differences observed between the photometer and the model data result from the uncertainties in the aerosol composition as seen on the refractive index values, but also from the underestimation of the aerosol mass concentrations. The summer bias is most likely related to an underestimation of secondary organic species by the CHIMERE model: There are large uncertainties in precursor emissions and above all in the chemical processes leading to SOA formation. As previously mentioned the wind resuspended and natural eroded dust particles, which are not taken into account in the model, could significantly contribute to the lack of the aerosol load in spring and summer time periods. This mass underestimation will be confirmed in the next section by the comparison with lidar measurements. We have to notice that the Sun photometer considers the AOT due to the whole atmosphere column, while the model only takes into account the first $5 \mathrm{~km}$, which could also lead to model underestimation, especially in the presence of high-altitude suspended desert aerosols.

\subsubsection{Single-Scattering Albedo (SSA)}

[34] Another valuable optical indicator of the model behavior is the single-scattering albedo. Figure 5 shows that the model tends to underestimate the observed SSA over the study period, except in September. The observed mean values vary from 0.69 to 0.84 , while the simulated ones range from 0.68 to 0.75 with less monthly variability. The bias is particularly important in February, March, and May, months during which the model also indicates an important overestimation of the imaginary part of the refractive index. This suggests that the simulated aerosols are more absorbent than the observed ones especially during winter and spring months.

[35] The comparison with AERONET data shows that aerosol optical parameters are rather correctly reproduced, on average, by CHIMERE for the considered period. We conclude that the model optical parameters can be used to compute backscattering profiles for the comparison with the lidar measurements.

\subsection{Sensitivity Study of the AOT}

[36] In this section we try to identify possible model deficiencies by performing sensitivity tests. First of all, size sections are not equally contributing to the total AOT. Table 4 shows that, for each month, more than $89 \%$ of

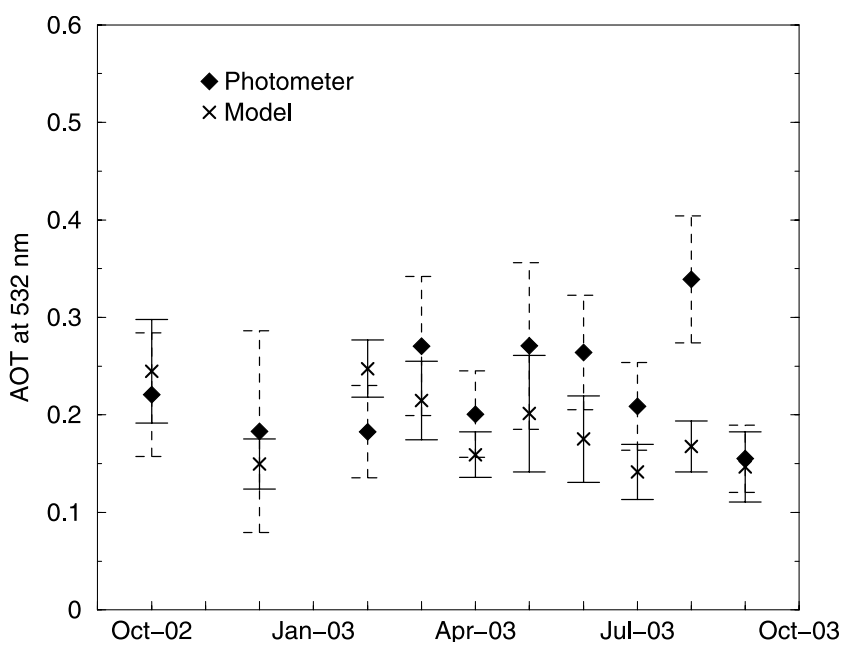

Figure 4. Monthly mean aerosol optical thickness at $532 \mathrm{~nm}$, issued from Sun photometer measurements and CHIMERE simulations at Palaiseau, France, between October 2002 and September 2003. 


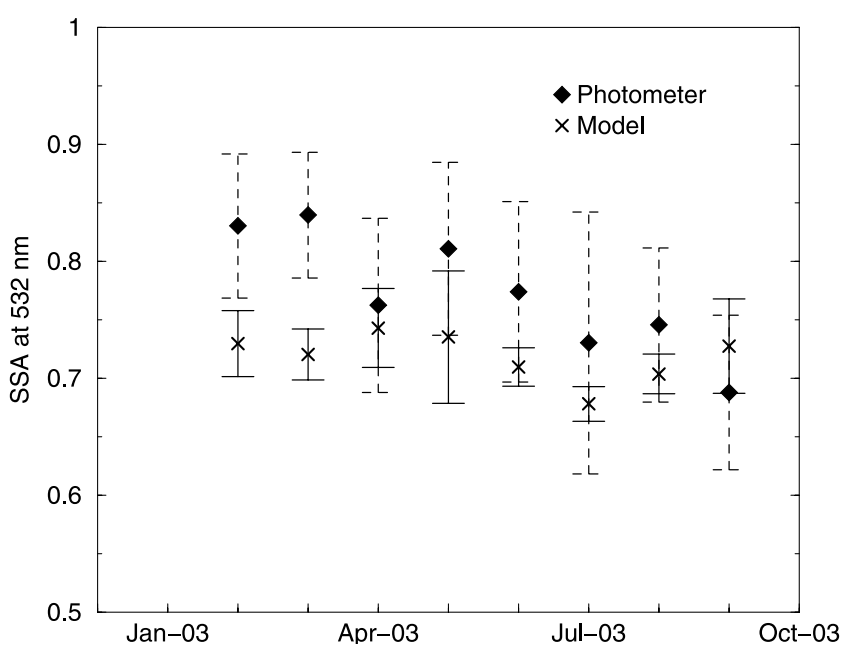

Figure 5. Monthly mean single-scattering albedo at $532 \mathrm{~nm}$, issued from Sun photometer measurements and CHIMERE simulations at Palaiseau, France, between January and September 2003.

the integrated optical thickness is due to the accumulation mode (model sections 3 and 4) corresponding to aerosol radius from 0.08 to $1.25 \mu \mathrm{m}$. The nucleation and the coarse modes have a smaller effect, less than $4 \%$ and $7 \%$, respectively. These results are in good agreement to those found during the ESQUIF campaign over Paris (P. Chazette et al., Optical properties of urban aerosol from airborne and ground in situ measurements performed over Paris area, the ESQUIF program, submitted to Journal of Geophysical Research, 2004). A possible bias in the aerosol mass must therefore be sought in this mode.

[37] Second, Bessagnet et al. [2004] demonstrated the ability of the model to simulate nitrate, sulfate, and ammonium aerosol compounds, although they only used ground-level observations for the comparisons. A good candidate aerosol class for the AOT bias is the SOA class, because it is mainly located in the accumulation mode and because a comparison of simulations and observations for this class has not yet been possible. By trial and error, we found that multiplying by three the mass of the model
SOA compound provides a fairly good match between simulated and observed lidar signals especially during spring and summer months (see section 6). In the case of AOTs, the monthly mean predictions rise on average from $7 \%$ in winter to $28 \%$ in summer, and the normalized biases decrease from $4 \%$ in December to more than $20 \%$ in June (Table 5). However, the increase of the SOA during autumn and winter (except in December) contributes to the overestimation of photometer-derived AOT values, and the results are not improved. The increase in the SOA mass undeniably allows a better agreement between the observed and simulated AOT values in spring and summer period, but underestimation still remains (close to $15 \%$ in July and $36 \%$ in August).

[38] Furthermore, missing sources such as mineral compounds or sea salt can also contribute to the underestimation of the model aerosol mass. Putaud et al. [2003] propose an average composition of aerosol based on ground measurements in Europe: In "near city" sites the mineral dust accounts for $7 \%$ and $22 \%$ in fine (particles smaller than $2.5 \mu \mathrm{m}$ ) and coarse fraction (particles grater than $2.5 \mu \mathrm{m}$ ), respectively, while the sea salt contributes for $3 \%$ and $9 \%$, respectively. Adding these contributions to the simulated aerosol total mass would improve the results compared to the reference simulation, except in October and February: The monthly mean values increase from $6 \%$ to $10 \%$, and the normalized biases decrease from $4 \%$ to $11 \%$.

\section{Comparisons With Lidar Vertical Profiles}

\subsection{Case of 26 March 2003}

[39] In order to compare the model with the aerosol lidar data, a case study is first carried out. The pollution episode of 26 March 2003 is chosen to illustrate our comparison. The episode is characterized by stable windless anticyclonic conditions over France, favoring the formation of aerosol pollution. Figure 6 shows a map of mean $\mathrm{PM}_{10}$ concentrations simulated by CHIMERE over the Paris area between 1100 and 1600 UTC, together with the AIRPARIF ground stations corresponding measurements (indicated by the little square boxes on the map). The formation of a $\mathrm{PM}_{10}$ plume is observed in the southwest of Paris, with mean concentrations greater than $50 \mu \mathrm{g} \mathrm{m}^{-3}$. The comparison with ground stations principally located

Table 4. Contribution of Each Section of the Model to the Mean AOT at $532 \mathrm{~nm}^{\mathrm{a}}$

\begin{tabular}{|c|c|c|c|c|c|c|}
\hline \multirow[b]{2}{*}{ Month } & \multicolumn{6}{|c|}{ Percentage of mean AOT at $532 \mathrm{~nm}(\%)$} \\
\hline & $\begin{array}{c}\text { Section 1 } \\
(0.005-0.02 \mu \mathrm{m})\end{array}$ & $\begin{array}{c}\text { Section } 2 \\
(0.02-0.08 \mu \mathrm{m})\end{array}$ & $\begin{array}{c}\text { Section } 3 \\
(0.08-0.3 \mu \mathrm{m})\end{array}$ & $\begin{array}{c}\text { Section } 4 \\
(0.3-1.25 \mu \mathrm{m})\end{array}$ & $\begin{array}{c}\text { Section } 5 \\
(1.25-5 \mu \mathrm{m})\end{array}$ & $\begin{array}{c}\text { Section } 6 \\
(5-20 \mu \mathrm{m}) \\
\end{array}$ \\
\hline October 2002 & 0.0 & 3.7 & 68.3 & 24.1 & 3.8 & 0.1 \\
\hline November 2002 & & - & - & - & - & - \\
\hline December 2002 & 0.0 & 3.0 & 74.5 & 21.1 & 1.4 & 0.0 \\
\hline January 2003 & - & - & - & - & - & - \\
\hline February 2003 & 0.0 & 3.2 & 77.0 & 18.3 & 1.5 & 0.0 \\
\hline March 2003 & 0.0 & 2.2 & 73.8 & 22.2 & 1.8 & 0.0 \\
\hline April 2003 & 0.1 & 3.8 & 72.0 & 22.3 & 1.8 & 0.0 \\
\hline May 2003 & 0.0 & 2.1 & 66.9 & 26.8 & 4.1 & 0.1 \\
\hline June 2003 & 0.0 & 3.4 & 65.1 & 26.5 & 4.9 & 0.1 \\
\hline July 2003 & 0.0 & 3.7 & 64.3 & 27.2 & 4.7 & 0.1 \\
\hline August 2003 & 0.1 & 3.6 & 59.8 & 29.6 & 6.8 & 0.1 \\
\hline September 2003 & 0.0 & 4.0 & 64.1 & 27.8 & 4.1 & 0.0 \\
\hline
\end{tabular}

${ }^{\mathrm{a}}$ Contributions are given in percent. The limit radius of each section is indicated in parentheses. 
Table 5. Comparison of Observed and Simulated AOTs for the Reference Scenario (1), the Scenario (2) With SOA Increased by $300 \%$, and the Scenario (3) Including Mineral Dust and Sea Salt

\begin{tabular}{|c|c|c|c|c|c|c|c|c|c|c|}
\hline \multirow[b]{2}{*}{ AOT, $532 \mathrm{~nm}$} & \multirow[b]{2}{*}{$O$} & \multicolumn{3}{|c|}{ Reference 1} & \multicolumn{3}{|c|}{ Scenario 2} & \multicolumn{3}{|c|}{ Scenario 3} \\
\hline & & $M$ & Normalized Bias, ${ }^{\mathrm{a}} \%$ & RMS & $M$ & Normalized Bias, ${ }^{\mathrm{a}} \%$ & RMS & $M$ & Normalized Bias ${ }^{\mathrm{a}} \%$ & RMS \\
\hline October 2002 & 0.223 & 0.245 & 9.9 & 0.087 & 0.281 & 26.0 & 0.113 & 0.268 & 20.2 & 0.100 \\
\hline November 2002 & - & - & - & - & - & - & - & - & - & - \\
\hline December 2002 & 0.183 & 0.149 & -18.6 & 0.101 & 0.156 & -14.8 & 0.095 & 0.159 & -13.1 & 0.099 \\
\hline January 2003 & - & - & - & - & - & - & - & - & - & - \\
\hline February 2003 & 0.183 & 0.247 & 35.0 & 0.109 & 0.270 & 47.5 & 0.123 & 0.267 & 45.9 & 0.125 \\
\hline March 2003 & 0.271 & 0.215 & -25.8 & 0.111 & 0.255 & -5.9 & 0.101 & 0.231 & -14.8 & 0.103 \\
\hline April 2003 & 0.201 & 0.159 & -20.9 & 0.093 & 0.185 & -8.0 & 0.087 & 0.170 & -15.4 & 0.091 \\
\hline May 2003 & 0.277 & 0.201 & -27.4 & 0.141 & 0.242 & -12.6 & 0.126 & 0.222 & -19.9 & 0.140 \\
\hline June 2003 & 0.262 & 0.175 & -33.2 & 0.159 & 0.229 & -12.6 & 0.190 & 0.189 & -27.9 & 0.157 \\
\hline July 2003 & 0.209 & 0.142 & -32.1 & 0.111 & 0.177 & -15.3 & 0.125 & 0.151 & -27.8 & 0.108 \\
\hline August 2003 & 0.339 & 0.168 & -50.4 & 0.226 & 0.217 & -36.0 & 0.205 & 0.181 & -46.6 & 0.218 \\
\hline September 2003 & 0.155 & 0.147 & -5.2 & 0.091 & 0.182 & 17.4 & 0.114 & 0.157 & 1.3 & 0.098 \\
\hline
\end{tabular}

${ }^{\mathrm{a}} \mathrm{Bias}(\%)$ is computed as follows: normalized bias $(\%)=100 \sum\left(M_{i}-O_{i}\right) / \sum\left(O_{i}\right)$; the root mean square is defined as RMS $=\sqrt{\frac{1}{N} \sum_{i}\left(M_{i}-O_{i}\right)^{2}}$; where $N$ is the number of samples given in Table 3 for each month, $O_{i}$ are the observations and $M_{i}$ are the simulations.

near the city of Paris shows a good agreement between model simulations and ground measurements. However, the site of Prunay, located in the western part of the domain (see Figure 1), was also equipped with a reference instrument for $\mathrm{PM}_{10}$ measurement (PARTISOL). For the meteorological conditions encountered (temperature from $15^{\circ} \mathrm{C}$ to $20^{\circ} \mathrm{C}$ ), using the PARTISOL working at $20^{\circ} \mathrm{C}$ instead of TEOM instrument operating at $50^{\circ} \mathrm{C}$, should provide more accurate measurements of $\mathrm{PM}_{10}$ because it avoids the evaporation of semivolatile species. Indeed, the

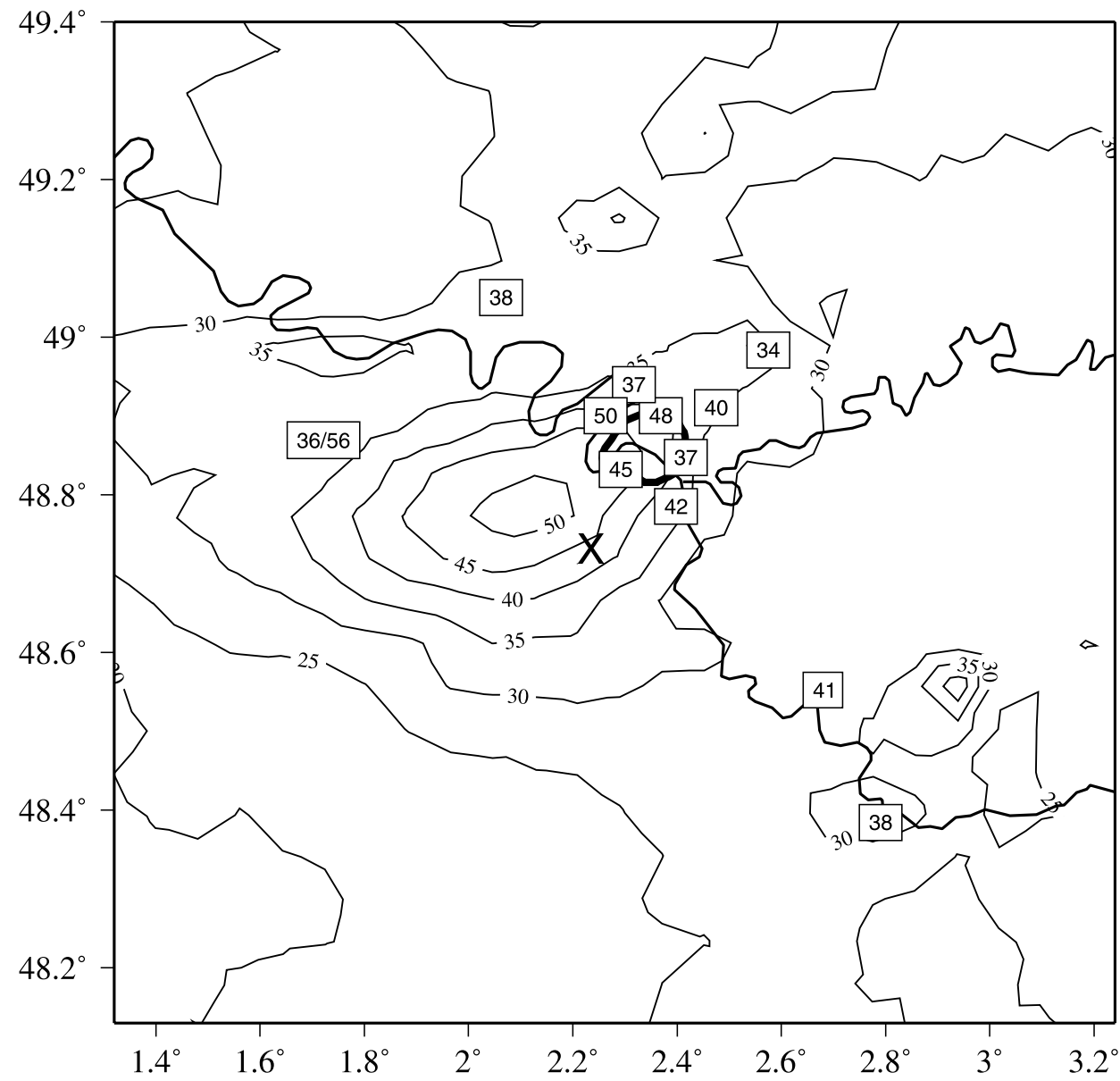

Figure 6. $\mathrm{PM}_{10}$ mean concentrations $\left(\mu \mathrm{g} \mathrm{m}^{-3}\right)$ as computed by CHIMERE model and observed by AIRPARIF network (ground stations indicated by square boxes) for a polluted day between 1100 and 1600 UTC. Palaiseau experimental site is indicated by a cross. 


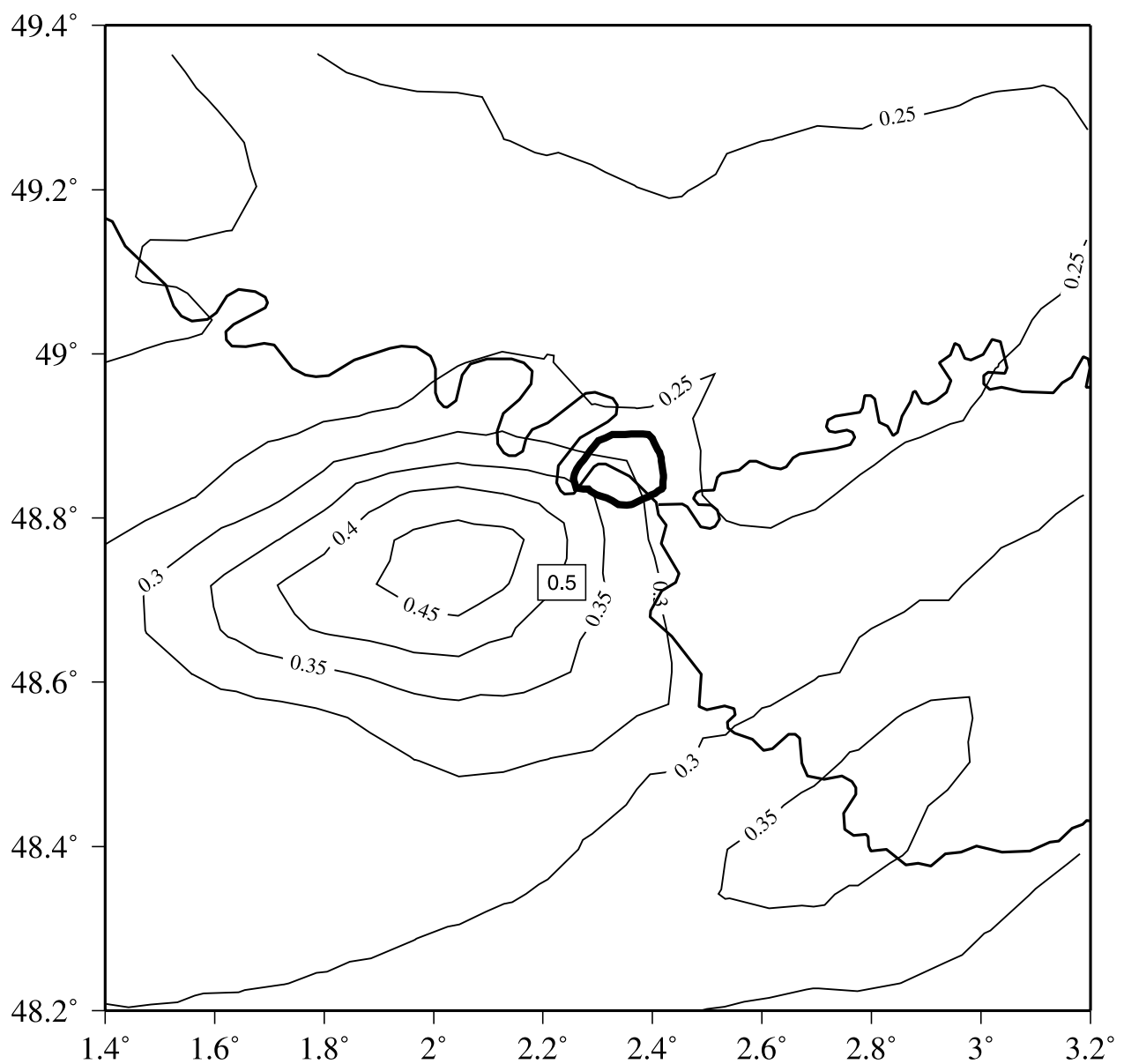

Figure 7. Column integrated aerosol optical thickness computed by CHIMERE model for 26 March 2003 between 1100 and 1600 UTC and observed by Sun photometer located at the site of Palaiseau (square box).

semivolatile material is known to be lost with routinely used devices, like the TEOM monitor used in AIRPARIF stations, and consequently, the $\mathrm{PM}_{10}$ concentrations are underestimated by $20 \%$ up to $50 \%$, depending on the season and the site [van Loon et al., 2003]. The reference instrument of the Prunay station (about $30 \mathrm{~km}$ west of Paris) gives high $\mathrm{PM}_{10}$ concentrations (56 instead of $36 \mu \mathrm{g} \mathrm{m}^{-3}$ ) suggesting that the real $\mathrm{PM}_{10}$ concentrations are probably underestimated at the others stations. The $\mathrm{PM}_{10}$ concentrations retrieved by the model are therefore also probably underestimated.

[40] The aerosol plume is also characterized by its optical signature in the AOT fields (Figure 7). The AOT values simulated by the model reach a maximum of 0.45 inside the plume, because of secondary aerosol formation and particle growth, thus making them more efficient for light extinction. The high AOT values are not located over the center of the city as one could expect, but clearly in the downwind plume. The mean AOT value of 0.5 observed at Palaiseau is comparatively higher than those retrieved by the model.

[41] In order to evaluate the ability of the model to reproduce the daily variation of the aerosols vertical distribution (that depends on the local emissions and atmospheric mixing conditions) we compute the logarithm of the elastic backscattered lidar range-corrected signal (LRCS) and compare it to the observed one for this particular day. Figure 8 shows a complex vertical structure of the observed atmosphere in the early afternoon by lidar observations. Three different layers can be distinguished: a planetary boundary layer (PBL) that contains the major part of the aerosol load, a residual layer (RL) visible until 1300 UTC, and an aerosol layer located between 2 and $3.5 \mathrm{~km}$ particularly well defined in the late morning. The model simulates correctly the vertical structure of the convective boundary layer, but not the thin aerosol layer (between 2 and $2.5 \mathrm{~km}$ ) and hardly the residual layer. The timing of the development of the boundary layer is fairly well reproduced. The top of the aerosol layer rises from $1 \mathrm{~km}$ in the morning to a maximum height of $3 \mathrm{~km}$ at $1500 \mathrm{UTC}$ and begins to fall after 1600 UTC.

[42] The hourly mean profiles of the LRCS shown in Figure 9 allow a more accurate comparison between the lidar and the model data. A good agreement between the model and observations is readily seen for the afternoon simulations, even though the model tends to underestimate the aerosol load after 1500 UTC. The morning residual layer also reveals significant underestimations. These underestimations can be due to missing sources in the inventory as well as problems of mixing and advection during 

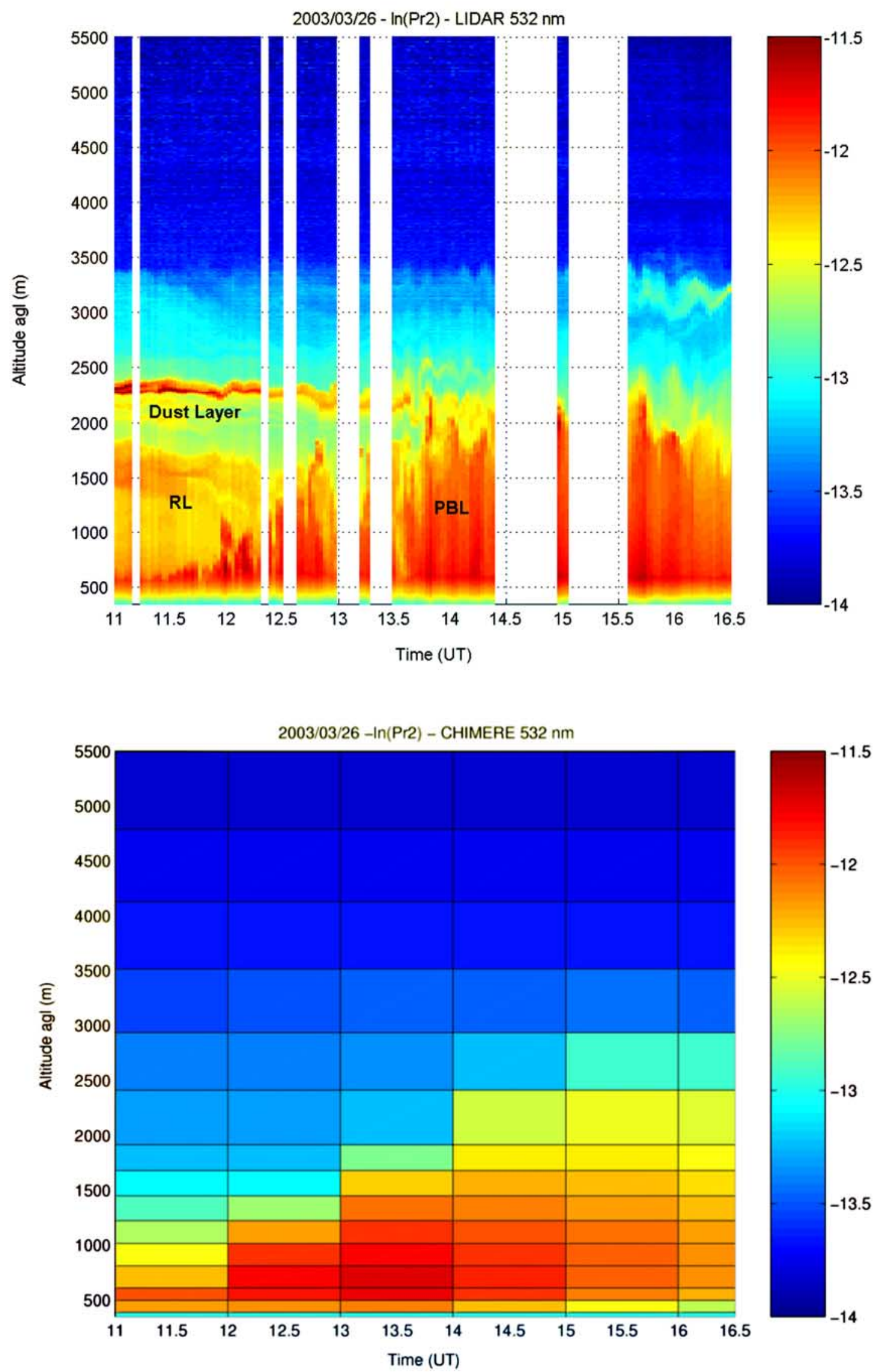

Figure 8

11 of 19 

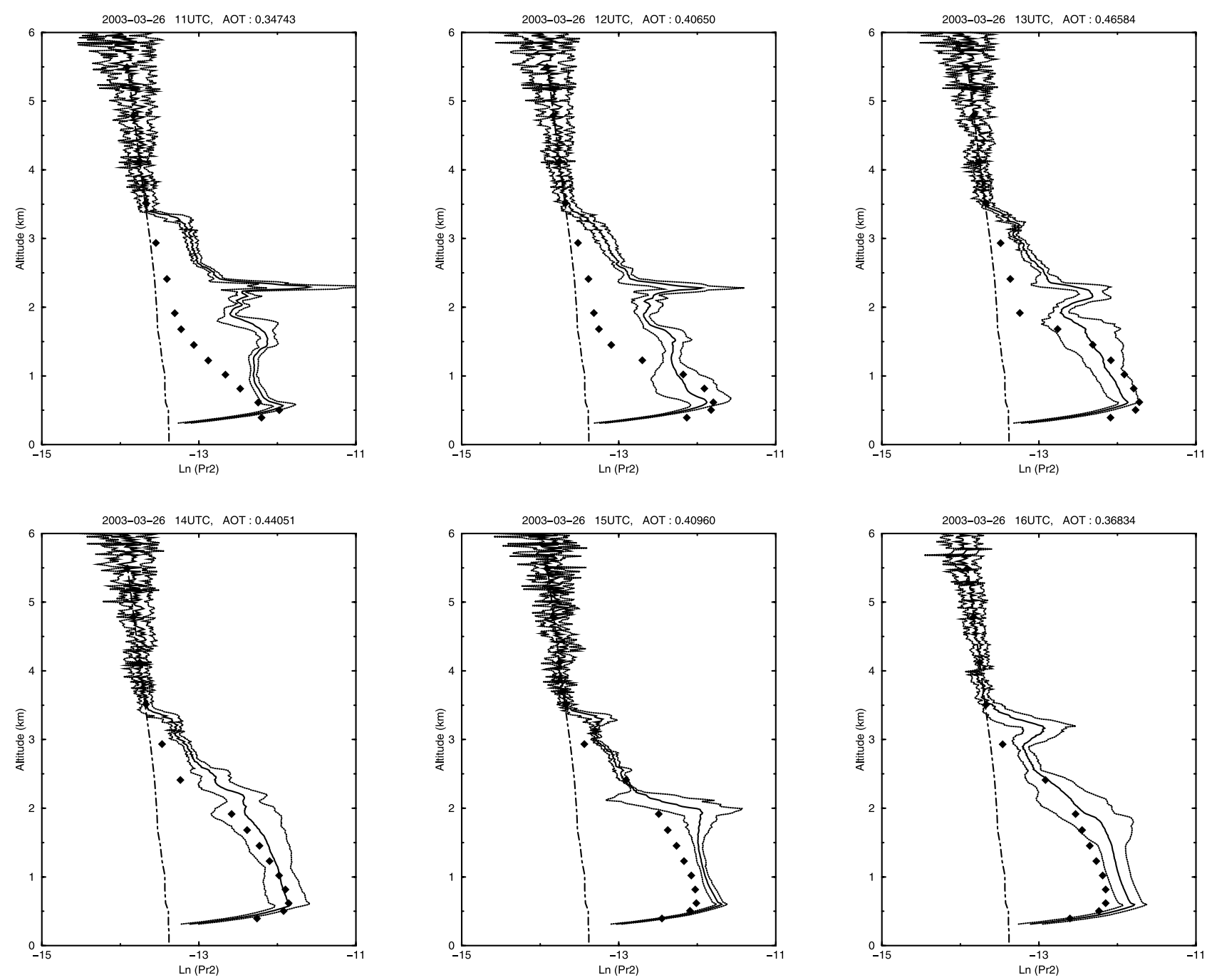

Figure 9. Comparison between the hourly mean backscattering vertical profiles observed by lidar (central solid line) and simulated by CHIMERE (diamonds) at Palaiseau on 26 March 2003 from 0900 to 1600 UTC. The variability of the lidar profile within an hour is also drawn (outer lines). The molecular profile is plotted using a dot-dashed line. Data below $300 \mathrm{~m}$ are not plotted because of the visibility restrictions of the lidar near the ground.

nighttime. The thin but concentrated aerosol layer observed between 2 and $2.5 \mathrm{~km}$ in the early afternoon is missing in the model simulation. The lidar backscatter profiles display typical signatures of desert mineral dust layers. Furthermore, the lidar linear depolarization ratio is much stronger for aerosol layer observed between 2 and $2.5 \mathrm{~km}$ than in the lower aerosol layers, showing that the upper layer is composed of non spherical particles, that is in agreement with a dust origin. The presence of Saharan dust aerosols is consistent with the back trajectories displayed in Figure 10. However, tracking air masses over several days using backtrajectories is difficult, and only a chemical analysis of the aerosol itself would ascertain this result. Saharan mineral aerosol emission fluxes are not yet accounted for in anyway in our model, and hence they could not reproduce this phenomenon.

\subsection{Statistical Analyses}

[43] The ability of the model to simulate the aerosol vertical load in the lower troposphere is now assessed by systematic comparisons of the observed and simulated lidar LRCS profiles. Owing to the meteorological conditions and constraints linked to the use of a lidar, there are a limited number of days when the lidar was running and measurements could be taken (Table 6). However, for these days, several hours are available for the comparisons. In order to

Figure 8. Daytime evolution of the vertical distribution of the aerosol lidar range-corrected signal (RCS) at $532 \mathrm{~nm}$, (top) observed by the lidar at Palaiseau during a high air pollution episode of 26 March 2003 and (bottom) simulated by CHIMERE. Various layers, such as planetary boundary layer (PBL), residual layer (RL), and dust layer are also indicated. 


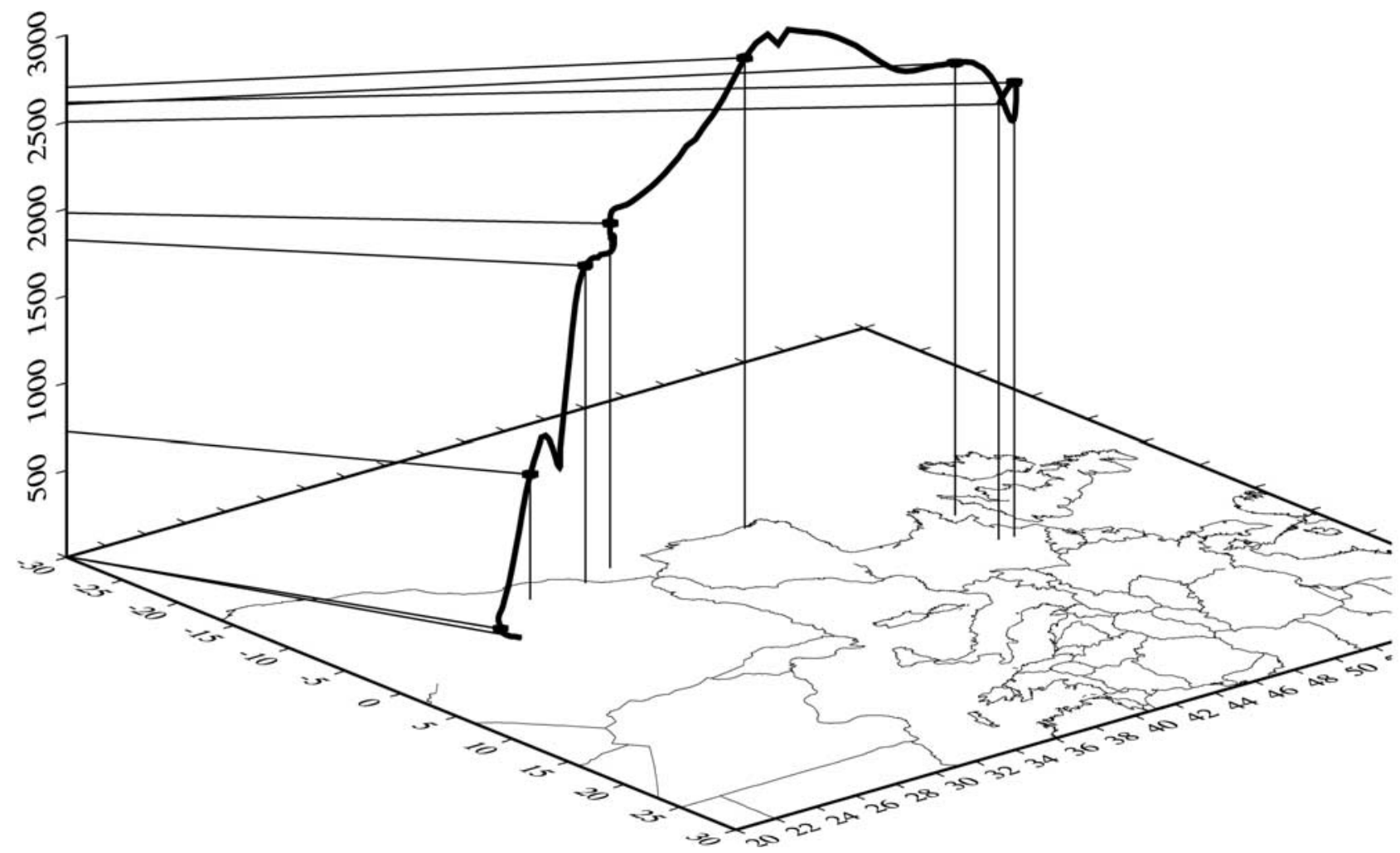

Figure 10. Backward trajectory ending at 1100 UTC 26 March 2003 at Palaiseau, computed using National Oceanic and Atmospsheric Administration (NOAA) Hybrid Single-Particle Lagrangian Integrated Trajectory (HYSPLIT) model and FNLF meteorological data (courtesy of NOAA Air Resources Laboratory, http://www.arl.noaa.gov).

smooth the signal, the lidar profiles are averaged over an hour, and only cloudless data periods are considered in the present study.

\subsubsection{Boundary Layer Height}

[44] Before comparing optical parameters, we first examine whether the boundary layer height is correctly reproduced by the model on average. For such a comparison we use the lidar and model backscattering profiles. The boundary layer height is taken as the altitude where the signal vertical gradient is strongest [Menut, 1999]. Owing to the occurrence of the multiple aerosol layers in some situations the detection of the boundary layer height is not reliable. Consequently, the number of available data for comparison is limited (67 values for considered profiles). The absence of systematic biases of the model is demonstrated on Figure 11. However, considering the simplicity of this

Table 6. Lidar Measurements at Palaiseau Between October 2002 and April 2003 in Cloudiness Conditions

\begin{tabular}{lcc}
\hline \multicolumn{1}{c}{ Month } & Number of Days & Number of Hours \\
\hline October 2003 & 2 & 8 \\
November 2002 & 4 & 6 \\
December 2002 & 2 & 8 \\
January 2003 & - & - \\
February 2003 & 6 & 23 \\
March 2003 & 8 & 44 \\
April 2003 & 4 & 19 \\
\hline
\end{tabular}

algorithm and the complexity of real situations, the results contain a large degree of uncertainty.

\subsubsection{Mean Profile}

[45] In Figure 12, the daily variation of mean backscattering profiles is calculated for both lidar observations and model predictions. The profiles show that the aerosol load

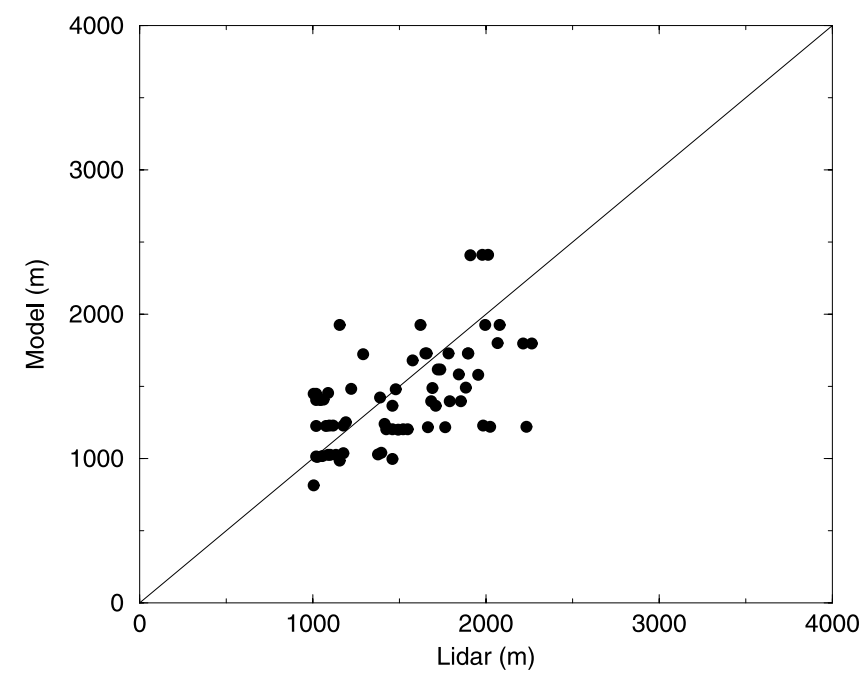

Figure 11. Scatter diagram of lidar-derived versus modelderived boundary layer height for the period from October 2002 to April 2003. 

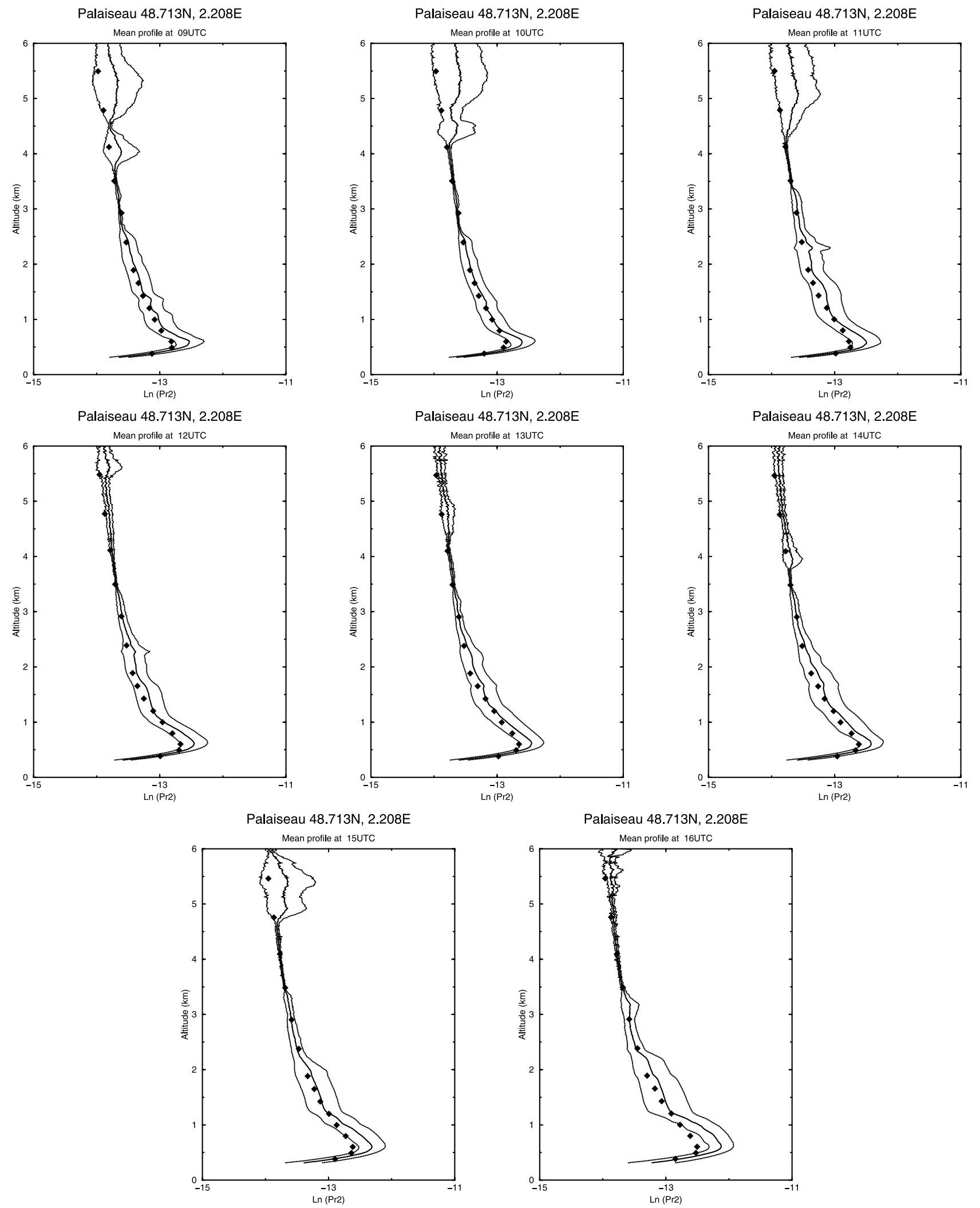

Figure 12. Comparison between the mean hourly lidar RCS vertical profiles observed by lidar (solid line) and the profiles simulated by CHIMERE (diamonds) at Palaiseau between 0900 and 1600 UTC and averaged from October 2002 to April 2003. The error bars are indicated by outer lines. Data are not shown below $300 \mathrm{~m}$ because of visibility restrictions of the lidar near the ground. 

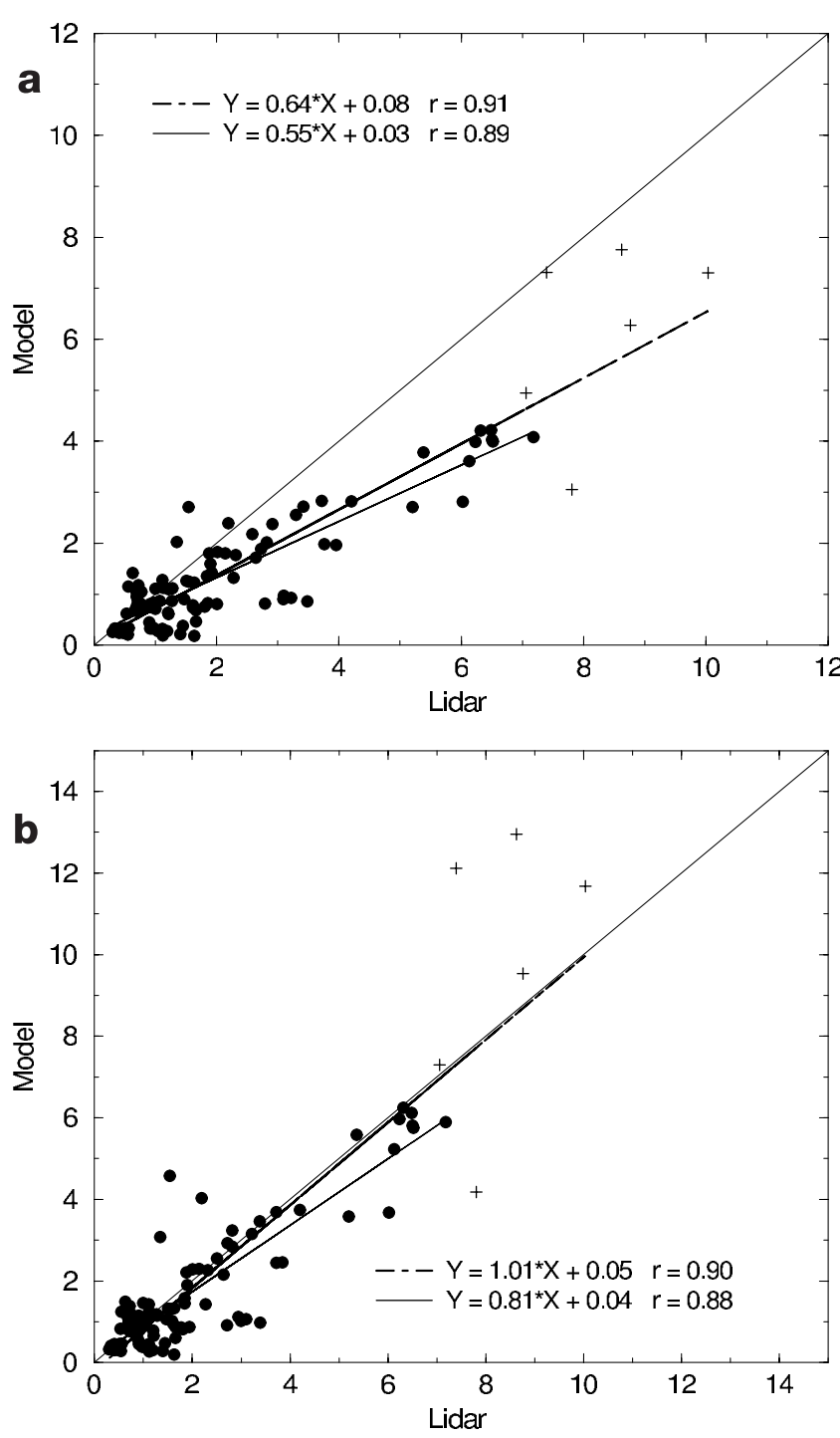

Figure 13. Scatterplot of simulated versus observed integrated $\operatorname{Pr}^{2}$ values (times $10^{-3}$ ) between $300 \mathrm{~m}$ and $3 \mathrm{~km}$ from October 2002 to April 2003 for the (a) reference scenario and (b) scenario with increased secondary organic species. Only the aerosol component is compared (the molecular part is not taken into account). The linear regression slope with (black line) and without (gray line) the episode of 26 March and correlation coefficients are also indicated.

accumulates in the boundary layer during the day. The model systematically underestimates the mean lidar profile in the middle of the boundary layer especially during the late afternoon: The aerosol loading is underestimated by more than $20 \%$. However, the model produces a satisfactory shape of the mean vertical profile.

\subsubsection{Comparison of Integrated Profiles}

[46] In order now to compare the ability of the model to simulate the variability of the profiles, we calculate the integrated $\operatorname{Pr}^{2}$ lidar values between $300 \mathrm{~m}$ and $3 \mathrm{~km}$ for each available profile. The scatterplot of simulated versus observed integrated profiles shown in Figure 13a confirms the underestimation of aerosol load by the model within the boundary layer by about $30 \%$, particularly during the pollution events: The linear regression slope reaches 0.64 for all considered profiles and 0.55 if high values corresponding to the episode of 26 March (influenced by Saharan dust) are excluded.

\subsubsection{Comparison for Various Model Levels}

[47] In order to avoid possible error compensations in integrated $\operatorname{Pr}^{2}$ lidar profiles, we also compared lidar and model profiles at various model levels (Figure 14). For the comparison, the lidar values are averaged over the corresponding model layers. According to their altitude, the comparison points can be divided into three groups: points located below $500 \mathrm{~m}$ (Figure 14a), affected by the geometric form factor; points within the mixed layer from 500 to about $1500 \mathrm{~m}$ (Figures $14 \mathrm{~b}$ and $14 \mathrm{c}$ ); and those above $1500 \mathrm{~m}$ located in the PBL transition zone (Figure $14 d)$. The very clear underestimation within the mixed layer due to the lack of the aerosol load in the model (Figure 14b) is also present in the transition zone and above the mixed layer (Figures 14c and 14d). The underestimated values in the transition zone generally coincide with the model underestimation of the boundary layer height. Therefore these points (indicated by triangles) are situated within the observed and above the model boundary layer. Figure 14d also shows that the dust layers present on 26 March (indicated by squares) contribute a lot to the model underestimation. The corresponding correlation coefficients vary from 0.71 to 0.92 , depending on the model layer.

\subsection{Sensitivity Study of the Simulated Lidar Profile}

[48] As in section 5, we evaluate here the impact of artificially increasing by a factor 3 the SOA mass and introducing mineral compounds and sea salt on the predicted backscattering profiles. The error statistics presented in Tables 7 and 8 show that the increase of the SOA leads to the better agreement between model and observations within the boundary layer. In this layer and above $500 \mathrm{~m}$, the absolute value of normalized biases decreases from 9 to $12 \%$ in the morning and from 7 to $14 \%$ in the afternoon. However, in the PBL transition zone, the model underestimation is replaced by an overestimation of the aerosol load, but the dispersion among the observed and simulated values is reduced as suggested by RMS errors. For all layers, the RMS errors generally decrease from 2 to $18 \%$, except at 600 $\mathrm{m}$ in the afternoon because of a model overestimation at that level. The correlation coefficient remains high, exceeding 0.7. The improvement of the comparison results by the increase of the SOA is also visible in the integrated profiles (Figure 13b): The linear regression slope reaches 0.81 instead of 0.55 for the reference scenario.

[49] Furthermore, we also find that the impact of the introduction of mineral material and sea salt on lidar backscattering power is less significant, as those particles contribute principally to the coarse aerosol mode which is not very efficient in terms of backscattering at the wavelength of $532 \mathrm{~nm}$. In this case, the decrease of normalized biases and RMS errors is less than $5 \%$ in average.

\section{Conclusions}

[50] In this paper we attempted to provide objective elements for the validation of the vertical structure of the CHIMERE chemistry transport model in its current aerosol 
$\operatorname{Ln}(\operatorname{Pr} 2)$ at mean altitude of $490 \mathrm{~m}$

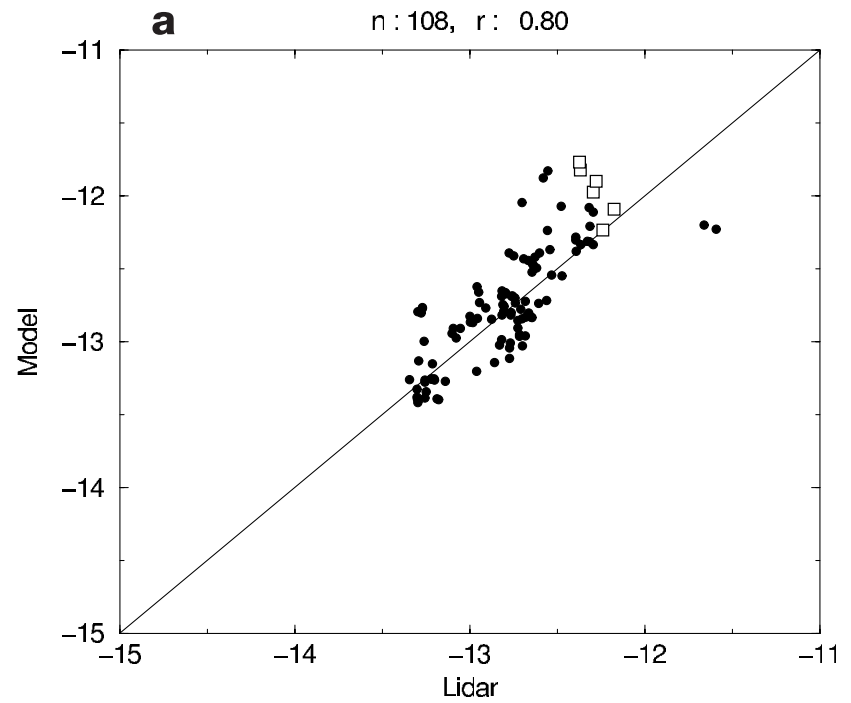

$\operatorname{Ln}(\operatorname{Pr} 2)$ at mean altitude of $997 \mathrm{~m}$

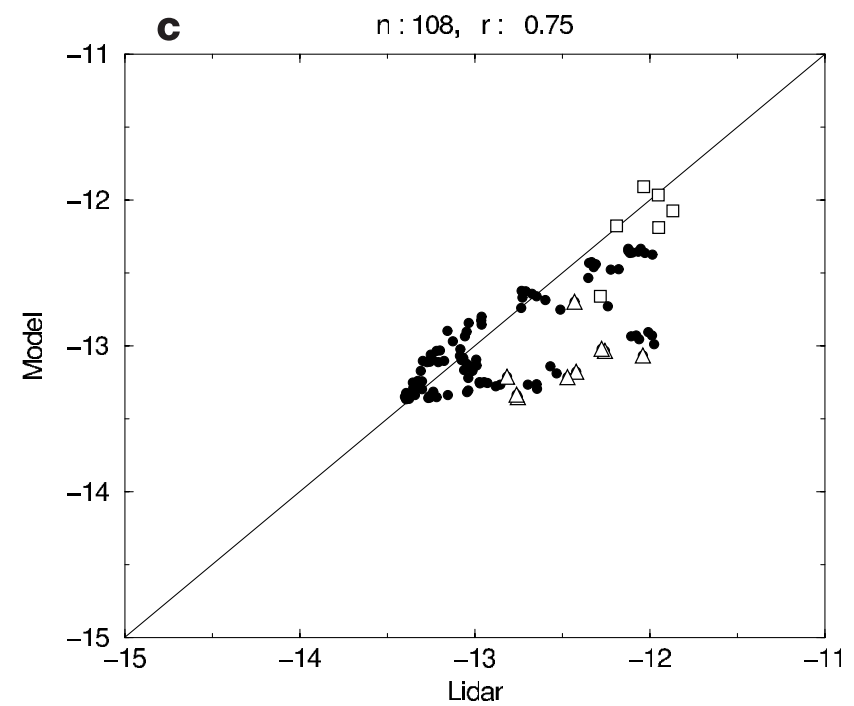

$\operatorname{Ln}(\mathrm{Pr} 2)$ at mean altitude of $796 \mathrm{~m}$

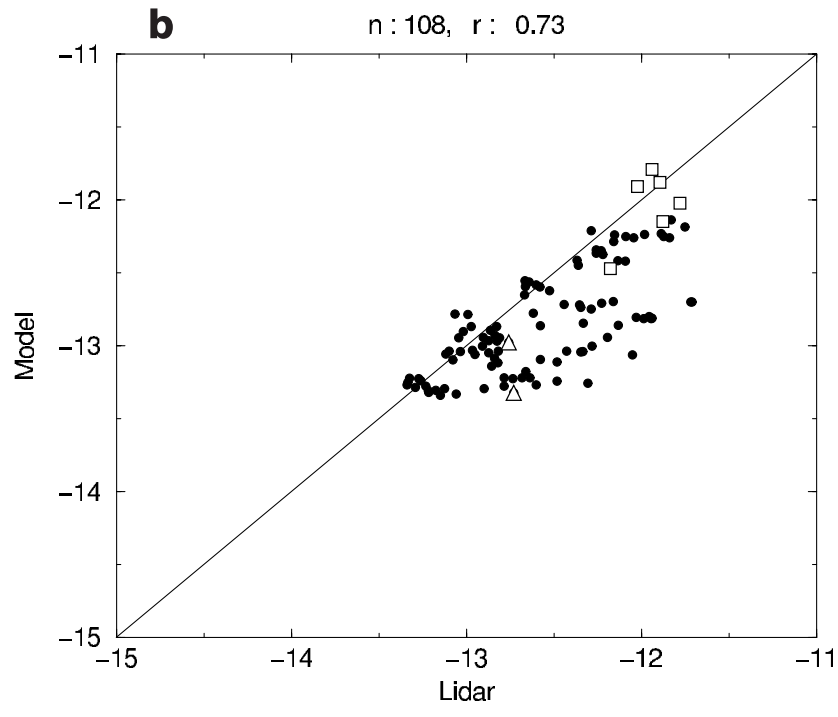

$\operatorname{Ln}(\operatorname{Pr} 2)$ at mean altitude of $1888 \mathrm{~m}$

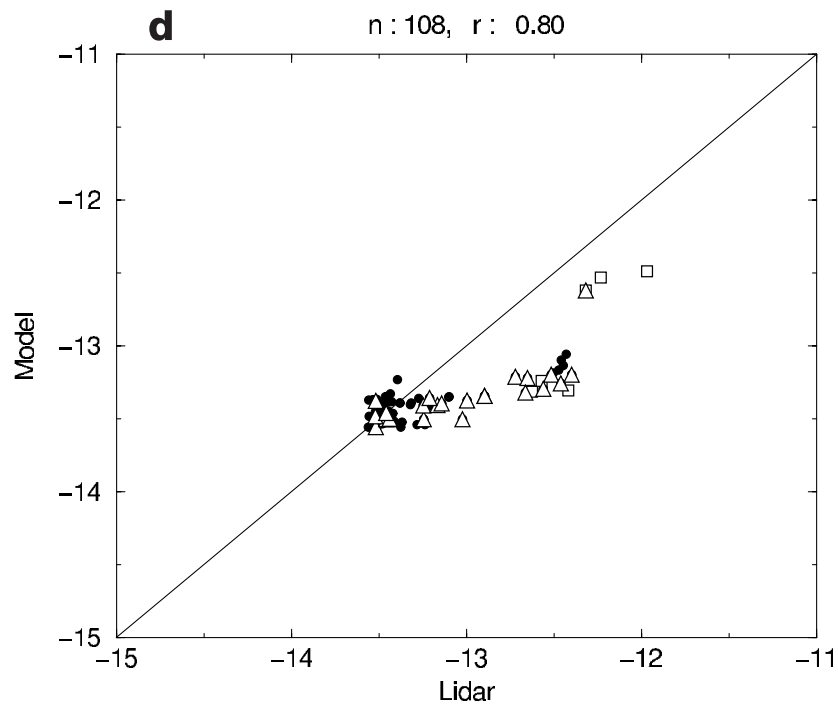

Figure 14. Scatter diagrams of $\operatorname{Ln}\left(\operatorname{Pr}^{2}(z)\right)$ as defined by equation (9) for measured versus modeled lidar profiles at different model levels: (a) below $500 \mathrm{~m}$ of altitude, (b) in the mixing layer, (c) in the transition zone, and (d) above the PBL top. Points situated above the model boundary layer height (BLH) for which the model underestimates the lidar BLH are indicated by triangles, and the 26 March episode is indicated by squares. Lidar profiles were averaged over the model vertical layers. The number of available data $(n)$ and correlation coefficients $(r)$ are also indicated.

version. The validation is made by comparing a number of elastic volume backscattering lidar profiles over the site of Palaiseau near Paris with their simulated equivalent. The comparison is made directly on the range-corrected backscattering lidar signal. Model simulations are also compared, on monthly averages, with measurements of optical parameters using a Sun photometer. All these comparisons experiments use data collected as often as possible between October 2002 and September 2003.

[51] The model is able to reproduce with reasonable skill both the observed aerosol optical thickness and the vertical elastic backscatter lidar profiles. The comparison with Sun photometer measurements shows that the model tends to underestimate the monthly mean values of AOT by more than $20 \%$ in spring and up to $50 \%$ in summer time period. Other optical parameters related to the aerosol composition, such as complex refractive index and single-scattering albedo, are predicted with acceptable errors: They are generally underestimated, except the imaginary part of the refractive index that is overestimated in winter and spring. Above all, this evaluation of aerosol optical properties clearly demonstrates that these latter can be used to simulate an elastic backscattering lidar signal.

[52] The comparison with backscattering lidar profiles allows the evaluation of the ability of the model to simulate the aerosol vertical distribution. First of all, the general shape of lidar signals is quite well simulated on the average, which means (1) that the MM5 meteorological model has 
Table 7. Comparison of Observed and Simulated Backscatter Mean Profiles Between 0800 and 1100 UTC at Palaiseau From October 2002 to April 2003 for the Reference Scenario (1), the Scenario (2) With Secondary Organic Species Increased by 300\%, and the Scenario (3) Including Mineral Dust and Sea Salt ${ }^{\mathrm{a}}$

\begin{tabular}{|c|c|c|c|c|c|c|c|c|c|c|}
\hline & \multicolumn{10}{|c|}{ Altitude, m } \\
\hline & 490 & 600 & 796 & 997 & 1203 & 1426 & 1654 & 1888 & 2387 & 2916 \\
\hline $\mathrm{M}_{\mathrm{OBS}}$ & 0.237 & 0.715 & 0.782 & 0.546 & 0.392 & 0.310 & 0.287 & 0.219 & 0.139 & 0.089 \\
\hline \multicolumn{11}{|c|}{ Scenario 1} \\
\hline Normalized bias, \% & 1.5 & -25.2 & -28.7 & -15.0 & -6.4 & -7.4 & -29.9 & -33.3 & -25.0 & -46.2 \\
\hline RMS & 0.232 & 0.269 & 0.350 & 0.229 & 0.207 & 0.167 & 0.228 & 0.240 & 0.227 & 0.195 \\
\hline Corrected & 0.79 & 0.85 & 0.79 & 0.86 & 0.87 & 0.94 & 0.91 & 0.84 & 0.84 & 0.79 \\
\hline \multicolumn{11}{|c|}{ Scenario 2} \\
\hline Normalized bias, $\%$ & 41.1 & -13.4 & -19.1 & -3.2 & 7.1 & 6.5 & -18.9 & -22.5 & -12.6 & -37.5 \\
\hline RMS & 0.282 & 0.241 & 0.316 & 0.217 & 0.198 & 0.137 & 0.195 & 0.214 & 0.204 & 0.181 \\
\hline Corrected & 0.81 & 0.86 & 0.78 & 0.85 & 0.88 & 0.95 & 0.91 & 0.92 & 0.87 & 0.83 \\
\hline \multicolumn{11}{|c|}{ Scenario 3} \\
\hline Normalized bias, $\%$ & 26.1 & -18.1 & -23.1 & -8.8 & 0.1 & -1.2 & -25.2 & -29.0 & -20.3 & -43.3 \\
\hline RMS & 0.252 & 0.247 & 0.324 & 0.217 & 0.203 & 0.156 & 0.214 & 0.232 & 0.222 & 0.191 \\
\hline Corrected & 0.79 & 0.85 & 0.79 & 0.86 & 0.87 & 0.94 & 0.91 & 0.84 & 0.83 & 0.79 \\
\hline
\end{tabular}

${ }^{a}$ The molecular component is not taken into account. Under $500 \mathrm{~m}$ the comparison depends on the geometric factor and is not really significant. Number of samples is 40 .

no particular bias in simulating the daytime height of the boundary layer and (2) that the mixing rate within the boundary layer is such that the aerosol mean vertical distributions are represented correctly. Second, there is a clear underestimation of the lidar signal within the boundary layer and above. Many factors could lead to such a behavior. The primary anthropogenic emissions may be underestimated, in which case one should in principle observe a rather seasonally uniform bias. Such is not the case: The bias is much higher in summer than in winter. Therefore processes typical to summertime aerosol formation can be incriminated such as secondary organic aerosol formation and dust emission by wind erosion of dry soil. Our knowledge about the first process is highly uncertain, and wind blown dust is not accounted for in our model. We also performed sensitivity experiments showing that both processes could be responsible for the model bias. However, the missing mineral components (mineral dust and sea salt) composed principally of coarse particles are not the primary cause of the underestimation as they are not efficient in terms of aerosol optical properties: The coarse modes account for less than $7 \%$ of the backscattering effect at $532 \mathrm{~nm}$, while the accumulation mode (particles from 0.08 to $1.25 \mu \mathrm{m}$ in radius) accounts for more than $89 \%$. Finally, the aerosol load bias above the boundary layer is probably due to several factors, among which the lack of long-range transport of fine Saharan dust in the model. Such a bias could also stem from insufficient exchange between the boundary layer and the free troposphere, because of a too rough parameterization of turbulent processes in the model. We detailed an example (26 March 2003) that illustrates all these problems.

Table 8. Comparison of Observed and Simulated Backscatter Mean Profiles Between 1200 and 1600 UTC at Palaiseau From October 2002 to April $2003^{\mathrm{a}}$

\begin{tabular}{|c|c|c|c|c|c|c|c|c|c|c|}
\hline & \multicolumn{10}{|c|}{ Altitude, $\mathrm{m}$} \\
\hline & 490 & 600 & 796 & 997 & 1203 & 1426 & 1654 & 1888 & 2387 & 2916 \\
\hline $\mathrm{M}_{\mathrm{OBS}}$ & 0.319 & 0.827 & 1.002 & 0.864 & 0.643 & 0.437 & 0.352 & 0.310 & 0.228 & 0.110 \\
\hline \multicolumn{11}{|c|}{ Scenario 1} \\
\hline Normalized bias, $\%$ & 30.0 & -13.3 & -23.2 & -22.3 & -17.6 & -3.3 & -13.0 & -29.5 & -34.2 & -34.6 \\
\hline RMS & 0.325 & 0.255 & 0.384 & 0.371 & 0.329 & 0.219 & 0.216 & 0.263 & 0.259 & 0.170 \\
\hline Corrected & 0.73 & 0.83 & 0.69 & 0.73 & 0.76 & 0.88 & 0.92 & 0.88 & 0.78 & 0.68 \\
\hline \multicolumn{11}{|c|}{ Scenario 2} \\
\hline Normalized bias, $\%$ & 84.0 & 5.7 & -9.4 & -9.5 & -4.5 & 11.9 & 0.9 & -18.2 & -24.4 & -25.7 \\
\hline RMS & 0.448 & 0.307 & 0.365 & 0.359 & 0.321 & 0.212 & 0.178 & 0.223 & 0.235 & 0.160 \\
\hline Corrected & 0.75 & 0.83 & 0.70 & 0.73 & 0.77 & 0.89 & 0.93 & 0.89 & 0.80 & 0.71 \\
\hline \multicolumn{11}{|c|}{ Scenario 3} \\
\hline Normalized bias, $\%$ & 50.6 & -6.0 & -17.8 & -17.0 & -12.1 & 3.0 & -7.4 & -24.9 & -29.8 & -30.3 \\
\hline RMS & 0.357 & 0.245 & 0.359 & 0.354 & 0.320 & 0.216 & 0.203 & 0.249 & 0.251 & 0.167 \\
\hline Corrected & 0.73 & 0.83 & 0.70 & 0.73 & 0.76 & 0.88 & 0.92 & 0.88 & 0.78 & 0.69 \\
\hline
\end{tabular}

${ }^{\mathrm{a}}$ The molecular component is not taken into account. Number of samples is 68 . 
[53] In our study showed that the backscatter lidar provides very useful information on the quantitative determination of the aerosol load in the lower troposphere and allows the validation of mesoscale aerosol models. This work, performed only at one particular site, calls for a generalization of the comparisons to other European lidar measurement sites in frame of the EARLINET project situations [Bösenberg et al., 2003], and thus it could be promising for the use of space-borne lidar systems (e.g., CALIPSO validation).

[54] Acknowledgments. The authors would like to acknowledge the SIRTA team (Christophe Pietras, Christophe Boitel, Florian Lapouge, Bernard Romand, Maurice Grall), who helped collecting and interpreting lidar data. We also thank L. Menut (LISA), T. Kerzenmacher (IPSL), G. Roux (Météo-France), R. Armante (IPSL), P. Flamant (IPSL), and F. Gibert (IPSL) for their scientific support and O. Blanchard (INERIS) for providing PARTISOL data. This work has been financially supported by ADEME and AIRPARIF.

\section{References}

Angström, A. (1964), The parameters of atmospheric turbidity, Tellus, 16, $64-75$.

Ansmann, A., et al. (2003), Long-range transport of Saharan dust to northern Europe: The 11-16 October outbreak observed with EARLINET, J. Geophys. Res., 108(D24), 4783, doi:10.1029/2003JD003757.

Aumont, B., F. Chervier, and S. Laval (2003), Contribution of HONO sources to the $\mathrm{NO}_{x} / \mathrm{HO}_{x} / \mathrm{O}_{3}$ chemistry in the polluted boundary layer, Atmos. Environ., 37, 487-498.

Balis, D., A. Papayannis, E. Galani, F. Marenco, V. Santacesaria, E. Hamonou, P. Chazette, I. Ziomas, and C. Zerefos (1999), Tropospheric LIDAR aerosol measurements and Sun photometric observations at Thessaloniki, Greece, Atmos. Environ., 34, 925-932.

Bennet, B. G., J. G. Kretzchmar, G. G. Akland, and H. W. Koning (1985), Urban air pollution worldwide, Environ. Sci. Technol., 19, 298-304.

Berge, E. (1993), Coupling of wet scavenging of sulphur to clouds in a numerical weather prediction model, Tellus, Ser. B, 45, 1-22.

Bessagnet, B., A. Hodzic, R. Vautard, M. Beekmann, L. Rouil, and R. Rosset (2004), Aerosol modeling with CHIMERE-First evaluation at continental scale, Atmos. Environ., 38, 2803-2817.

Blond, N., and R. Vautard (2004), Three-dimensional ozone analyses and their use for short-term ozone forecast, J. Geophys. Res., 109, D17303, doi:10.1029/2004JD004515.

Blond, N., L. Bel, and R. Vautard (2003), Three-dimensional ozone data analysis with an air quality model over the Paris area, J. Geophys. Res., 108(D17), 4744, doi:10.1029/2003JD003679.

Bösenberg, J., et al. (2003), EARLINET: A European aerosol research lidar network to establish an aerosol climatology, Rep. 348, 200 pp., MaxPlanck Inst. for Meteorol., Hamburg, Germany.

Chazette, P. (2003), The monsoon aerosol extinction properties at Goa during INDOEX as measured with lidar, J. Geophys. Res., 108, 4187, doi: $10.1029 / 2002 J D 002074$.

Chazette, P., and C. Liousse (2000), A case study of optical and chemical ground apportionment for urban aerosols in Thessaloniki, Atmos. Environ., 35, 2497-2506.

Collis, R. T. H., and P. B. Russell (1976), Lidar measurements of particles and gases by elastic backscattering and differential absorption, Top. Appl. Phys., 14(8), 89-97.

Derognat, C., M. Beekmann, M. Baeumle, D. Martin, and H. Schmidt (2003), Effect of biogenic volatile organic compound emissions on tropospheric chemistry during the Atmospheric Pollution Over the Paris Area (ESQUIF) campaign in the Ile-de-France region, J. Geophys. Res., 108(D17), 8560, doi:10.1029/2001JD001421

Dubovik, O., and M. D. King (2000), A flexible inversion algorithm for retrieval of aerosol optical properties from sun and sky radiance measurements, J. Geophys. Res., 105, 20,673-20,696.

Dubovik, O., A. Smirnov, B. N. Holben, M. D. King, Y. J. Kaufman, T. F. Eck, and I. Slutsker (2000), Accuracy assessment of aerosol optical properties retrieval from Aerosol Robotic Network (AERONET) Sun and sky radiance measurements, J. Geophys. Res., 105, 9791-9806.

Dubovik, O., B. N. Holben, T. F. Eck, A. Smirnov, Y. J. Kaufman, M. D. King, D. Tanré, and I. Slutsker (2001), Variability of absorption and optical properties of key aerosol types observed in worldwide locations, J. Atmos. Sci., 59, 590-608.
Dudhia, J. (1993), A nonhydrostatic version of the Penn State/NCAR mesoscale model: Validation tests and simulation of an Atlantic cyclone and clod front, Mon. Weather Rev., 121, 1493-1513.

Eleftheriadis, K., D. Balis, I. Colbeck, and N. Manalis (1998), Atmospheric aerosol and gaseous species in Athens, Greece, Atmos. Environ., 32, 2183-2191.

Fernald, F. G., B. M. Herman, and J. A. Reagan (1972), Determination of aerosol height distributions by lidar, J. Appl. Meteorol., 11, 482-489.

Gelbard, F., and J. H. Seinfeld (1980), Simulation of multicomponent aerosol dynamics, J. Colloid Interface Sci., 78, 485-501.

Guelle, W., Y. J. Balkanski, J. E. Dibb, M. Schulz, and F. Dulac (1998), Wet deposition in a global size-dependent aerosol transport model: 2. Influence of the scavenging scheme on ${ }^{210} \mathrm{~Pb}$ vertical profiles, surface concentrations, and deposition, J. Geophys. Res., 103, 28,875-28,891.

Guelle, W., Y. J. Balkanski, M. Schulz, B. Marticorena, G. Bergametti, C. Moulin, R. Arimoto, and K. D. Perry (2000), Modeling the atmospheric distribution of mineral aerosol: Comparison with ground measurements and satellite observations for yearly and synoptic timescales over the North Atlantic, J. Geophys. Res., 105, 1997-2012.

Haeffelin, M. C., et al. (2003), SIRTA, a ground-based atmospheric observatory for clouds, aerosols and water vapor, Notes Activ. Instrum. 37, 46 pp., Inst. Pierre Simon Laplace, Paris. (Available at http://www.ipsl.jussieu.fr/documentation/NAI/Notes.htm)

Hamonou, E., P. Chazette, D. Balis, F. Dulac, X. Schneider, E. Galani, G. Ancellet, and A. Papayannis (1999), Characterization of the vertical structure of Saharan dust export to the Mediterranean basin, J. Geophys. Res., 104, 2257-2270.

Hänel, G. (1976), The properties of atmospheric aerosols as functions of the relative humidity at thermodynamic equilibrium with the surrounding moist air, Adv. Geophys., 19, 73-188.

Hass, H., M. Van Loon, C. Kessler, R. Stern, J. Matthijsen, F. Sauter, Z. Zlatev, J. Langner, V. Foltescu, and M. Schaap (2003), Aerosol modeling: Results and intercomparison from European regional scale modeling systems, EUROTRAC 2 Rep., Eur. Exp. on Transp. and Transfer of Environ. Relevant Constituents in the Troposphere over Europe, Int. Sci. Secr., Munich, Germany.

Hoffman, M. R., and J. G. Calvert (1985), Chemical transformation modules for Eulerian acid deposition models, in The Aqueous Phase Chemistry, vol. 2, Rep. EPA/600/3-85/017, U.S. Environ. Protect. Agency, Research Triangle Park, N. C.

Holben, B. N., et al. (1998), AERONET-A federated instrument network and data archive for aerosol characterization, Remote Sens. Environ., 66, $1-16$.

Horowitz, L. W., et al. (2003), A global simulation of tropospheric ozone and related tracers: Description and evaluation of MOZART, version 2, J. Geophys. Res., 108(D24), 4784, doi:10.1029/2002JD002853.

Jacob, D. J. (2000), Heterogeneous chemistry and tropospheric ozone, Atmos. Environ., 34, 2131-2159.

Kulmala, M., A. Laaksonen, and L. Pirjola (1998), Parameterization for sulfuric acid/water nucleation rates, J. Geophys. Res., 103, 8301-8307.

Lattuati, M. (1997), Impact des émissions Européennes sur le bilan d'ozone troposhérique à l'interface de l'Europe et de l'Atlantique Nord: Apport de la modélisation lagrangienne et des mesures en altitude, Ph.D. thesis, Univ. é Pierre et Marie Curie, Paris.

Lee, Y. N., and S. E. Schwartz (1983), Kinetics of oxidation of aqueous sulfur (IV) by nitrogen dioxide, in Precipitation Scavenging, Dry Deposition and Resuspension, vol. 1, edited by H. R. Pruppacher, R. G. Semonin, and W. G. N. Slinn, pp. 453-470, Elsevier Sci., New York.

Lefrère, J. (1982), Etude par sondage laser de la basse atmosphère, Ph.D. thesis, Univ. é Paris 6, Paris.

Liousse, C., C. Devaux, F. Dulac, and H. Cachier (1995), Aging of savanna biomass burning aerosols: Consequences on their optical properties, J. Atmos. Chem., 22, 1-17.

Lurmann, F. W., A. S. Wexler, S. N. Pandis, S. Mussarra, N. Kumar, and J. H. Seinfeld (1997), Modeling urban and regional aerosols. II. Application to California's South Coast Air Bassin, Atmos. Environ., 31, $2695-2715$

Mallet, M. (2003), Etude des propriétés microphysiques et optiques de l'aérosol en zone périurbaine durant ESCOMPTE-Estimation de l'impact radiatif direct, Ph.D. thesis, Univ. é de Toulon et du Var, Toulon, France.

Measures, R. M. (1984), Laser Remote Sensing: Fundamentals and Applications, p. 208, Wiley-Interscience, Hoboken, N. J.

Menut, L. (1999), Urban boundary-layer height determination from lidar measurements over the Paris area, Appl. Opt., 38, 945-954.

Menut, L. (2003), Adjoint modeling for atmospheric pollution process sensitivity at regional scale, J. Geophys. Res., 108(D17), 8562, doi:10.1029/2002JD002549.

Mie, G. (1908), Beiträge zur Optik trüber Medien, speziell kolloidaler Metallösungen, Ann. Phys., 25(3), 377-445. 
Moulin, C., F. Dulac, C. E. Lambert, P. Chazette, I. Jankowiak, B. Chatenet, and F. Lavenu (1997), Long-term daily monitoring of Saharan dust load over ocean using Meteosat ISCCP-B2 data: 2. Accuracy of the method and validation using Sun photometer measurements, J. Geophys. Res., 102, 16,959-16,969.

Nenes, A., C. Pilinis, and S. N. Pandis (1998), ISORROPIA: A new thermodynamic model for inorganic multicomponent atmospheric aerosols, Aquat. Geochem., 4, 123-152.

Nenes, A., S. N. Pandis, and C. Pilinis (1999), Continued development and testing of a new thermodynamic aerosol module for urban and regional air quality models, Atmos. Environ., 33, 1553-1560.

Pankow, J. F. (1994), An absorption model of gas/particle partitioning of organic compounds in the atmosphere, Atmos. Environ., 28, 185-188.

Pelon, J., C. Flamant, P. Chazette, J. F. Léon, D. Tanré, M. Sicard, and S. K. Satheesh (2002), Characterization of aerosol spatial distribution and optical properties over the Indian Ocean from airborne lidar and radiometry during INDOEX '99, J. Geophys. Res., 107(D19), 8029, doi:10.1029/ 2001JD000402.

Putaud, J. P., et al. (2003), A European aerosol phenomenology: Physical and chemical characteristics of particulate matter at kerbside, urban, rural and background sites in Europe, Rep. EUR 20411 EN, Joint Res. Cent., Ispra, Italy. (Available at http://ccu.ei.jrc.it/ccu/)

Schmidt, H., and D. Martin (2003), Adjoint sensitivity of episodic ozone in the Paris area to emissions on the continental scale, J. Geophys. Res., 108(D17), 8561, doi:10.1029/2001JD001583.

Schmidt, H., C. Derognat, R. Vautard, and M. Beekmann (2001), A comparison of simulated and observed ozone mixing ratios for the summer of 1998 in Western Europe, Atmos. Environ., 35, 6277-6297.

Seinfeld, J. H., and S. N. Pandis (1998), Atmospheric Chemistry and Physics, John Wiley, Hoboken, N. J.

Sicard, M., P. Chazette, J. Pelon, J. G. Won, and S. C. Yoon (2002), Variational method for the retrieval of the optical thickness and the backscatter coefficient from multiangular lidar profiles, Appl. Opt., 41, $493-$ 502 .

Sillman, S., R. Vautard, L. Menut, and D. Kley (2003), $\mathrm{O}_{3}-\mathrm{NO}_{x}-\mathrm{VOC}$ sensitivity and $\mathrm{NO}_{x}$-VOC indicators in Paris: Results from models and
Atmospheric Pollution Over the Paris Area (ESQUIF) measurements, J. Geophys. Res., 108(D17), 8563, doi:10.1029/2002JD001561.

Tsyro, S. (2002), First estimates of the effect of aerosol dynamics in the calculation of $\mathrm{PM}_{10}$ and $\mathrm{PM}_{2.5}$, Rep. MSC-W Note 4/02, Norw. Meteorol. Inst., Olso. (Available at www.emep.int)

Ulaby, F. T., R. K. Moore, and A. K. Fung (1943), Microwave Remote Sensing Fundamentals and Radiometry, Artech House, Norwood, Mass. van Loon, M., J. P. Wesseling, H. A. C. Denier van der Gon, and A. J. H. Visschedijk (2003), Assessment of present and future $\mathrm{PM}_{10}$ concentrations, Rep. TNO-MEP-R2001, Neth. Organ. for Appl. Sci. Res., Apeldoorn.

Vautard, R., M. Beekmann, J. Roux, and D. Gombert (2001), Validation of a hybrid forecasting system for the ozone concentrations over the Paris area, Atmos. Environ., 35, 2449-2461.

Vautard, R., D. Martin, M. Beekmann, P. Drobinski, R. Friedrich, A. Jaubertie, D. Kley, M. Lattuati, P. Moral, B. Neininger, and J. Theloke (2003), Paris emission inventory diagnostics from ESQUIF airborne measurements and a chemistry transport model, J. Geophys. Res., 108(D17), 8564, doi:10.1029/2002JD002797.

Volz, F. E. (1973), Infrared optical constants of ammonium sulfate, Saharan dust, volcanic pumice and fly-ash, Appl. Opt., 12, 564-568.

M. Beekmann and P. Drobinski, Service d'Aéronomie, Institut PierreSimon Laplace, 75252 Paris, France.

B. Bessagnet, Institut National de l'Environnement Industriel et des Risques (INERIS), 60550 Verneuil en Halatte, France.

B. Chatenet, Laboratoire Interuniversitaire des Systèmes Atmosphériques, 94010 Créteil, France.

P. Chazette, Laboratoire des Sciences du Climat et de l'Environnement, Institut Pierre-Simon Laplace, 91191 Gif sur Yvette, France.

H. Chepfer, J. Cuesta, M. Haeffelin, A. Hodzic, Y. Morille, and R. Vautard, Laboratoire de Météorologie Dynamique, Institut Pierre-Simon Laplace, Palaiseau Cedex 1 91128, France. (hodzic@lmd.polytechnique.fr)

P. Goloub, Laboratoire d'Optique Atmosphérique, 59655 Villeneuve d'Ascq, France. 